\title{
Targeting the Annexin A1-FPR2/ALX pathway for host-directed therapy in dengue disease
}

2 Vivian V Costa ${ }^{1, \#, ~ M i c h e l l e ~ A ~ S u g i m o t o ~}{ }^{2,3, \#}$, Josy Hubner ${ }^{1}$, Caio S Bonilha ${ }^{2,4}$, Celso M Queiroz-Junior ${ }^{1}$, 3 Marcela Helena Gonçalves Pereira ${ }^{2}$, Jianmin Chen ${ }^{5}$, Thomas Gobbetti ${ }^{5}$, Gisele Olinto Libanio Rodrigues ${ }^{2}$,

4 Jordana L. Bambirra ${ }^{6}$, Ingredy Passos ${ }^{1}$, Carla Elizabeth Machado Lopes ${ }^{1}$, Thaiane P. Moreira ${ }^{6}$, Kennedy

5 Bonjour ${ }^{7}$, Rossana C. N. Melo ${ }^{7}$, Milton A. P. Oliveira ${ }^{8}$, Marcus Vinicius M. Andrade ${ }^{3}$, Lirlândia Pires

6 Sousa $^{9}$, Danielle Gloria Souza ${ }^{6}$, Helton da Costa Santiago ${ }^{2}$, Mauro Perretti ${ }^{5,10, \dagger}$, Mauro Martins Teixeira ${ }^{2, \dagger}, *$

7 'Department of Morphology, Institute of Biological Sciences, Universidade Federal de Minas Gerais,

8 Minas Gerais, Brazil.

$9 \quad{ }^{2}$ Department of Biochemistry and Immunology, Institute of Biological Sciences, Universidade Federal de 10 Minas Gerais, Minas Gerais, Brazil.

$11 \quad{ }^{3}$ School of Medicine, Universidade Federal de Minas Gerais, Minas Gerais, Brazil.

$12{ }^{4}$ Institute of Infection, Immunity and Inflammation, College of Medical, Veterinary and Life Sciences,

13 University of Glasgow, Glasgow, UK.

$14{ }^{5}$ William Harvey Research Institute, Barts and The London School of Medicine and Dentistry, Queen Mary 15 University of London, London, UK.

$16{ }^{6}$ Department of Microbiology, Institute of Biological Sciences, Universidade Federal de Minas Gerais, Belo 17 Horizonte, MG, Brazil.

$18{ }^{7}$ Department of Biology, Institute of Biological Sciences, Federal University of Juiz de Fora, Juiz de Fora, 19 MG, Brazil.

$20{ }^{8}$ Tropical Pathology and Public Health Institute, Universidade Federal de Goiás, Goiânia, Goiás, Brazil.

$21{ }^{9}$ Department of Clinical and Toxicological Analyses, School of Pharmacy, Universidade Federal de Minas 22 Gerais, Belo Horizonte, MG, Brazil.

$23 \quad{ }^{10}$ Centre for Inflammation and Therapeutic Innovation, Queen Mary University of London, London, UK.

$24 \quad$ \#These authors contributed equally to this work.

$25 \dagger$ These authors contributed equally to this work.

26 "Corresponding author: Mauro Martins Teixeira, Departamento de Bioquímica e Imunologia, Instituto de 27 Ciências Biológicas, Universidade Federal de Minas Gerais, Av. Antônio Carlos, 6627, CEP 31.270-901, 28 Belo Horizonte, Brazil. Email: mmtex.ufmg@ gmail.com. ORCID iD 0000-0002-6944-3008.

29 Short running title: AnxA1-FPR2/ALX is protective in dengue disease. 


\section{ABSTRACT}

31 Host immune responses contribute to dengue's pathogenesis and severity, yet the possibility that failure in

32 endogenous inflammation resolution pathways could characterise the disease has not been contemplated.

33 The pro-resolving protein Annexin A1 (AnxA1) is known to counterbalance overexuberant inflammation

34 and mast cell (MC) activation. We hypothesised that inadequate AnxA1 engagement underlies the cytokine

35 storm and vascular pathologies associated with dengue disease. Levels of AnxA1 were examined in the

36 plasma of dengue patients and infected mice. Immunocompetent, IFN $\alpha / \beta R^{--}$, AnxA1 ${ }^{-/-}$and FPR2/ALX ${ }^{-/-}$

37 mice were infected with Dengue virus (DENV) and treated with the AnxA1 mimetic peptide $\mathrm{Ac}_{2-26}$ for analysis. Additionally, the effect of $\mathrm{Ac}_{2-26}$ on DENV-induced $\mathrm{MC}$ degranulation was assessed in vitro and in vivo. We observed that circulating levels of AnxA1 were reduced in dengue patients and DENV-infected mice. While the absence of AnxA1 or its receptor FPR2/ALX aggravated illness in infected mice, treatment with AnxA1 agonistic peptide attenuated disease manifestations. Both clinical outcomes were attributed to modulation of DENV-mediated viral load-independent MC degranulation. We have thereby identified that

43 altered levels of the pro-resolving mediator AnxA1 are of pathological relevance in DENV infection, 44 suggesting FPR2/ALX agonists as a therapeutic target for dengue disease. 


\section{INTRODUCTION}

Dengue is caused by one of four serotypes of dengue virus (DENV1-4) transmitted by Aedes Aegypti and

A. Albopictus mosquitoes, affecting around 400 million people in 128 countries (Bhatt et al., 2013).

Occasionally, dengue infection develops into a potentially lethal complication identified as severe dengue,

typified by exacerbated systemic inflammation, vascular leakage, fluid accumulation, respiratory distress, severe bleeding, and/or organ impairment (Organization, 2009). No antiviral drug for dengue treatment is available, and the use of Dengvaxia ${ }^{\circledR}$ (CYD-TDV), the first dengue vaccine approved by the US Food and Drug Administration (FDA), has its limitations, such as the increased risk for development of severe dengue in the immune populations (The Lancet Infectious, 2018). Thus, the combination of these factors points to dengue as a major unmet clinical problem in countries affected by this disease (Shepard, Undurraga, Halasa, \& Stanaway, 2016; Stanaway et al., 2016).

The pathogenesis of severe dengue results from exacerbated host innate and adaptative immune responses to DENV. Among the target cells for DENV in humans, mast cells (MC) lining blood vessels undergo dramatic cellular activation in response to DENV, despite their high resistance to infection (Beatty et al., 2015; Modhiran et al., 2015; St John, Rathore, Raghavan, Ng, \& Abraham, 2013). As essential regulators of vascular integrity, MC activation evoked by DENV triggers the production of inflammatory cytokines (cytokine storm) and vascular leakage, which ultimately result in hypovolemic shock in severe dengue (St John, Rathore, et al., 2013; Syenina, Jagaraj, Aman, Sridharan, \& St John, 2015). This is substantiated by a positive correlation between circulating MCPT-1 levels and disease severity recently observed in paediatric and adult patients (A. P. S. Rathore et al., 2020; Tissera et al., 2017). In line with the suggested role of uncontrolled immune responses in the pathogenesis of DENV infection, pharmacological suppression of inflammation (Fu et al., 2014; Marques et al., 2015; Souza et al., 2009), MC stabilisation

67 (Morrison et al., 2017), and inhibition of MC-derived protease (A. P. Rathore et al., 2019) have shown to 
targeting excessive or misplaced inflammation may be a viable approach in treating severe dengue

70 infection.

71 Pro-resolving mediators are cell signalling molecules synthesised in a strict temporal and spatial fashion to

72 regulate the host response and prevent the excessive acute inflammatory reaction that damages the host

73 (Sugimoto, Vago, Perretti, \& Teixeira, 2019). The discovery of this active phase of inflammation has led

74 to a new awareness of how a disease can emerge, including the concept that dysregulation or 'failure' in

75 pro-resolving mechanisms might be involved in the pathogenesis of several chronic inflammatory disorders

76 (Eke Gungor, Tahan, Gokahmetoglu, \& Saraymen, 2014; Fredman et al., 2016; Murri et al., 2013; Schett

77 \& Neurath, 2018; Sena et al., 2013; Tabas \& Glass, 2013; Thul, Labat, Temmar, Benetos, \& Back, 2017;

78 Vong et al., 2012). The pro-resolving protein AnxA1 and its cognate receptor formyl peptide receptor 2

79 (FPR2/ALX) are known to bear anti-inflammatory properties in sterile settings (Fredman et al., 2015;

80 Galvao et al., 2017; Gimenes et al., 2015; Kusters et al., 2015; Leoni et al., 2015; Locatelli et al., 2014),

81 and to exert a degree of protection in infectious settings, such as experimental tuberculosis (Tzelepis et al.,

82 2015; Vanessa et al., 2015), sepsis (Amilcar S. Damazo et al., 2005; Gobbetti et al., 2014), pneumococcal

83 pneumonia (Machado et al., 2020; Tavares et al., 2016) and influenza (Schloer et al., 2019). AnxA1 has

84 been recently described to act as an endogenous modulator of MC degranulation in response to IgE/anti-

85 IgE or compound 48/80 (Parisi, Correa, \& Gil, 2019; Sinniah et al., 2019; Sinniah, Yazid, Perretti, Solito,

86 \& Flower, 2016; Yazid, Sinniah, Solito, Calder, \& Flower, 2013). Since AnxA1 is well known to counter

87 regulate overexuberant pro-inflammatory events and $\mathrm{MC}$ activation, we have hypothesised that an

88 imbalance between this anti-inflammatory/pro-resolving mediator and pro-inflammatory molecules could

89 be operating during dengue infection.

90 In the present work, we have analysed the role of the pro-resolving AnxA1-FPR2/ALX pathway as a

91 regulator of excessive inflammation observed in patients with the most severe forms of dengue infection.

92 Our results suggest that failure to trigger this molecular pathway may contribute to disease severity in 
94 in human dengue disease.

95

96

97

98

99

100

101

102

103

104

105

106

107

108

109

110

111

112

113

114

115

\section{METHODS}

\section{Ethics}

This study was carried out in accordance with the Brazilian Government's ethical and animal experiments regulations (Law 11794/2008). The experimental protocol was approved by the Institutional Animal Care and Use Committee of the Universidade Federal de Minas Gerais (CEUA/UFMG, Permit Protocol Numbers 169/2016 and 234/2019). All surgeries were performed under ketamine/xylazine anaesthesia, and all efforts were made to minimise animal suffering. Human sample collection was approved by the Committee on Ethics in Research of the Universidade Federal de Minas Gerais (Protocol Numbers 24832513.4.0000.5149 and 66128617.6.0000.5149). All patients have provided signed informed consent.

\section{Patient recruitment}

Dengue outpatients were recruited at Primary Care Center Jardim Montanhês and Santo Ivo Hospital. Inpatients were recruited in Odilon Behrens Metropolitan Hospital and Santa Casa Hospital. Healthy volunteers, negative for anti-DENV IgG (PanBio-Alere), were recruited in the community (Belo Horizonte, Minas Gerais, Brazil). Recruitment was done between the years of 2013-2016. Blood samples were obtained from 41 healthy donors and 60 dengue patients. Dengue patients were categorised into severe dengue (SD) and non-severe dengue (non-SD) groups using the 2009 World Health Organization (WHO) guidelines (WHO, 2009) and the expert physician's judgment of disease severity (Goncalves Pereira et al., 2020). All SD patients were in-hospitalised. Of the 60 dengue patients enrolled in this study, 29 were classified as SD, and 31 were non-SD patients. Patients were included in this study if DENV infection was confirmed by dengue specific IgM capture ELISA (PanBio-Alere) and/or real-time reverse transcriptasepolymerase chain reaction (RT-PCR) conducted on all blood samples. Individuals with comorbidities such 
as diabetes, autoimmune diseases or obesity were excluded from this study. Serum samples collected from

117 healthy volunteers and patients with confirmed DENV infection and a clear discharge diagnosis of either

118 SD or non-SD were selected for measuring plasma AnxA1 levels by ELISA.

119 Mice

Female BALB/c and C57BL/6 mice were obtained from the Center of Bioterism of Universidade Federal de Minas Gerais (UFMG), Brazil. Annexin A1 knockout mice (BALB/c background) (Hannon et al., 2003) and FPR2/ALX knockout mice (C57BL/6 background) (Dufton et al., 2010) were bred and maintained at animal facilities of the Immunopharmacology Laboratory of UFMG. Some experiments were conducted in type I interferon receptor-deficient mice (A129), SV129 background, obtained from Bioterio de Matrizes

125 da Universidade de Sao Paulo (USP), bred and maintained at animal facilities of the Immunopharmacology

126 Laboratory of the UFMG. For experiments, five-week-old wild-type mice and eight-week-old A129 mice 127 were kept under specific pathogen-free conditions at a constant temperature $\left(25^{\circ} \mathrm{C}\right)$ with free access to chow and water in a $12 \mathrm{~h}$ light/dark cycle.

Cell lines, monoclonal antibodies, and viruses

Vero and Aedes albopictus C6/36 cells were obtained from Banco de Células do Rio de Janeiro (BCRJ) and cultured in RPMI 1640 medium (Cultilab) or L15 medium (Cultilab), respectively, supplemented with 10\% of inactivated foetal bovine serum (Cultilab). For in vivo and in vitro experiments, low passage human clinical isolates of DENV serotypes DENV-1 (EDEN 2402), DENV-2 (EDEN 3295), DENV-3 (EDEN

134 863), and DENV-4 (EDEN 2270) were propagated in Aedes albopictus C6/36 cells, and the supernatants of 135 infected cells were harvested, filtered, concentrated, tittered by plaque assay, and stored at $-80{ }^{\circ} \mathrm{C}$ until use. 136 All in vivo studies with the infectious viruses were performed in a BSL-2 facility of the 137 Immunopharmacology lab of the Institute of Biological Sciences at UFMG. 
For DENV infection experiments, mice received an intravenous injection of $10^{6} \mathrm{PFU}$ (BALB/c WT, infection (A. S. Damazo, Yona, Flower, Perretti, \& Oliani, 2006; Galvao et al., 2017; Perretti, Ahluwalia, Harris, Goulding, \& Flower, 1993; Vago et al., 2012). A129 mice were treated with $\mathrm{Ac}_{2-26}(150 \mu \mathrm{g} / \mathrm{animal}$; i.p.) daily from day two post-infection until sacrifice (day five). Mice were randomly allocated into experimental groups using an MS Excel randomisation tool. All experiments were repeated at least twice.

\section{Blood parameters}

Murine blood was obtained from the cava vein in heparin-containing syringes at the indicated time points under ketamine and xylazine anaesthesia $(100 \mathrm{mg} / \mathrm{Kg}$ and $10 \mathrm{mg} / \mathrm{Kg}$, respectively). The final concentration of heparin was $50 \mathrm{U} / \mathrm{ml}$. Platelets were counted in a Neubauer chamber (Costa et al., 2014; Costa et al., 2012). Results are presented as the number of platelets per $\mu \mathrm{L}$ of blood. For haematocrit determination, blood was collected into heparinised capillary tubes (Perfecta) and centrifuged for $10 \mathrm{~min}$ in a haematocrit centrifuge (Fanem, São Paulo, Brazil) (Costa et al., 2014; Costa et al., 2012).

\section{Changes in vascular permeability}

The extravasation of Evans blue dye into the liver was used as an index of increased vascular permeability, as previously described (Costa et al., 2014; Saria \& Lundberg, 1983; St John, Rathore, et al., 2013). The amount of Evans blue in the tissue was obtained by comparing the extracted absorbance with a standard 


\section{Cytokines, chemokines and AnxA1 quantification}

164 The concentrations of murine CCL2, CCL5 and IL-6 in plasma samples and tissue homogenates were 165 measured using commercially available DuoSet ${ }^{\circledR}$ ELISA Development Kits (R\&D). The concentrations of 166 the MC-specific product MCPT1 in plasma samples were measured using a commercially available ELISA 167 Ready-SET-Go! ${ }^{\circledR}$ Kit (eBioscience). Human or murine AnxA1 ELISA kits (USCN Life Sciences Inc.) were 168 used to quantify plasma levels of AnxA1. All the immunoassays were performed according to 169 manufacturers' instructions.

\section{$170 \quad$ Virus titration}

171 A129 mice were assayed for viral titres in plasma, spleen, and liver. Blood samples were collected in 172 heparinised tubes and centrifuged at $3000 \mathrm{~g}$ for 15 minutes at room temperature. The plasma was collected 173 and stored at $-80{ }^{\circ} \mathrm{C}$ until assayed. For virus recovery from the spleen and liver, the organs were collected 174 aseptically in different time points and stored at $-80{ }^{\circ} \mathrm{C}$ until assayed. Tissue samples were weighed and 175 grounded using a pestle and mortar and prepared as 10\% (w/v) homogenates in RMPI 1640 medium without 176 foetal bovine serum (FBS). Viral load in the supernatants of tissue homogenates and plasma samples were 177 assessed by direct plaque assay using Vero cells as previously described (Costa et al., 2012). Results were 178 measured as plaque-forming units (PFU) per $100 \mathrm{mg}$ of tissue weight or per $\mathrm{ml}$ of plasma. The limit of 179 detection of the assay was $100 \mathrm{PFU} / \mathrm{g}$ of tissue or per $\mathrm{mL}$.

\section{Transaminase activity}

181 The alanine aminotransferase (ALT) activity was measured in individual serum samples from A129 mice, 182 using a commercially available colourimetric kit (Bioclin, Quibasa, Belo Horizonte, Brazil). Results are 183 expressed as $\mathrm{U} / \mathrm{L}$ of plasma.

\section{Histopathology}


Liver samples from euthanised mice were obtained at the indicated time points. After that, samples were immediately fixed in $10 \%$ neutral-buffered formalin for 24 hours and embedded in paraffin. Tissue sections (4 $\mu \mathrm{m}$ thicknesses) were stained with hematoxylin and eosin (H\&E) and evaluated under a microscope Axioskop 40 (Carl Zeiss, Göttingen, Germany) adapted to a digital camera (PowerShot A620, Canon, Tokyo, Japan). Histopathology score was performed as previously described (Costa et al., 2012), evaluating hepatocyte swelling, degeneration, necrosis, and haemorrhage added to a five-point score ( 0 , absent; 1 , minimal; 2, slight; 3, moderate; 4, marked; and 5, severe) in each analysis. A total of two sections for each animal were examined, and results were plotted as the mean of damage values in each mouse.

\section{Mast cell (MC) in vivo degranulation}

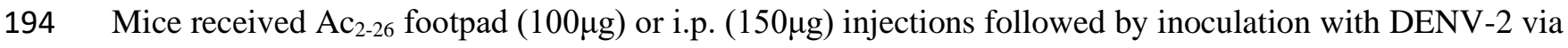
195 footpad injections. Three hours later, mice were euthanised and had their hind paws removed and fixed in $19610 \%$ neutral-buffered formalin for conventional histopathological processing. According to their 197 morphological characteristics, MCs were classified as degranulated or normal, as previously described (St 198 John et al., 2011).

Bone marrow-derived mast cell (BMMC) generation and in vitro degranulation

BMMCs were generated as previously described (Andrade et al., 2011; Radinger, Jensen, Swindle, \&

201 Gilfillan, 2015). After four weeks, BMMCs were verified by flow cytometry to be $>95 \%$ positive for the

202 MC surface marker c-kit (CD117). To assess degranulation of BMMC in response to DENV, cells were 203 mock-stimulated or stimulated with DENV-2 at MOI of 1 , for 30 minutes, at $37^{\circ} \mathrm{C}$, in HEPES degranulation 204 buffer (10 mM HEPES, $137 \mathrm{mM} \mathrm{NaCl}, 2.7 \mathrm{mM} \mathrm{KCl}, 0.4 \mathrm{mM}$ sodium phosphate, $5.6 \mathrm{mM}$ glucose, $1.8 \mathrm{mM}$ 205 calcium chloride, $1.3 \mathrm{mM}$ magnesium sulphate, $\mathrm{pH}$ 7.4). For some groups, BMMCs were incubated with 2061,10 or $100 \mu \mathrm{M} \mathrm{Ac}_{2-26}$ one hour before stimulation with DENV. Degranulation was determined from the 207 release of the granule marker $\beta$-hexosaminidase, as previously described (Andrade et al., 2011; Radinger 
et al., 2015). The experiment was repeated twice with BMMCs isolated from distinct animals and differentiated independently.

\section{Transmission electron microscopy}

211 BMMCs pre-treated or not with Ac2-26 peptide $(100 \mu \mathrm{M}, 1 \mathrm{~h})$ followed by mock-stimulation or stimulation 212 with DENV-2 (MOI of 1 for 30 minutes, at $37{ }^{\circ} \mathrm{C}$ ) were observed by transmission electron microscopy

213 (TEM). BMMCs obtained from three distinct animals were treated and stimulated individually. Unlike 214 tissue-housed mast cells, primary cell cultures of the mast cells can generate cells in different maturation 215 profiles, including early-stage and fully developed cells with typical secretory granules (Combs, 1971; JW, 216 1966). Thus, cells from the biological triplicate were pooled in each group to reach a suitable mature cell 217 number in our analysis.

218 Following treatment and stimulation, cells were immediately fixed in a mixture of freshly prepared 219 aldehydes (1\% paraformaldehyde and $1.25 \%$ glutaraldehyde) in $0.1 \mathrm{M}$ phosphate buffer, $\mathrm{pH} 7.3$, for $1 \mathrm{~h}$ at 220 room temperature and prepared for conventional TEM as before (Melo et al., 2009). Sections were mounted

221 on uncoated 200-mesh copper grids (Ted Pella) before staining with lead citrate and examined using a 222 transmission electron microscope (Tecnai Spirit G12; Thermo Fisher Scientific/FEI, Eindhoven, 223 Netherlands) at $120 \mathrm{kV}$. A total of 203 electron micrographs were analysed to investigate morphological 224 changes indicative of degranulation. Additionally, 1,116 secretory granules $(n=372, n=360$ and $n=384$ in 225 the mock, DENV-2 and DENV-2+Ac 2-26 groups, respectively) were counted in 45 electron micrographs 226 showing the entire cell profile and the granule diameters, as well as the numbers of fused granules were 227 quantified. Quantitative studies were performed using the Image J software (National Institutes of Health, 228 Bethesda, MD, United States). 
RNA from human plasma was obtained using PureLink Viral RNA/DNA Kits (Invitrogen). Amplifications were performed by qPCR using SuperScript III Platinum One-Step Quantitative RT-PCR System with ROX

232 (Invitrogen) according to the manufacturer's instructions in the presence of primers and probes described

233 previously (Goncalves Pereira et al., 2020; Hue et al., 2011) (Supplementary Table 1). For quantifying the

234 virus in the mouse, RNA was isolated with the RNeasy kit from Qiagen. Briefly, tissues were homogenised

235 with the machine TissueLyserII in a small amount of the buffer using ceramic beads. Then the

236 manufacturer's protocol to isolate the RNA was performed, followed by cDNA synthesis. For detecting

237 DENV-2 in the spleen, reverse primer 5' - TTGCACCAACAGTCAATGTCTTCAGGTTC was used for

238 cDNA synthesis, followed by RT-PCR using forward primer 5'-

239 TCAATATGCTGAAACGCGCGAGAAACCG $\quad$ and $\quad$ reverse 5 $^{\prime}$

240 CGCCACAAGGGCCATGAACAG. For detecting DENV-2 in the liver, reverse primer 5'-

241 GTAGCCTAGTTTGTGCAGCC was used for cDNA synthesis, and forward primer 5'-

242 GCAGCAGAGCCATATGGT and reverse primer 5'-GTAGCCTAGTTTGTGCAGCC for RT-PCR.

\section{Statistics}

244 GraphPad Prism 9.1.2 was used to determine statistical significance. Determination of sample size was

245 based on previous publications using the software G*Power 3.1 Software. The results were analysed using

246 appropriate statistical tests, as indicated in figure legends. Data are represented as mean $\pm \mathrm{SD}$.

\section{RESULTS}

\section{Annexin A1 plasma levels are reduced in dengue patients}

249 To ascertain how DENV infection impacts the expression dynamic of the pro-resolving molecule AnxA1

250 in humans, we measured the AnxA1 protein level in the plasma of DENV-infected patients (Fig. 1A).

251 Dengue patients ( $\mathrm{n}=60$ ) were grouped into non-SD (dengue patients that were treated at home as

252 outpatients, $\mathrm{n}=31$ ) and SD (dengue inpatient cases that met WHO criteria for hospitalisation, $\mathrm{n}=29$ ) 
253 (Goncalves Pereira et al., 2020). Demographics and laboratory characteristics are available in Table 1.

254 Groups were comparable for sex distribution. The proportion of patients showing secondary dengue 255 infection was not significantly different between the non-SD and SD groups. All patients with positive PCR

256 reactions were infected with DENV-1, in line with a report that DENV-1 was the predominant serotype

257 circulating in the city in which patients were recruited in the years of sample collection (Goncalves Pereira

258 et al., 2020). Outpatient evolution was confirmed by remote monitoring at the convalescent phase.

259 Interestingly, we have identified that plasma levels of AnxA1 were reduced compared to healthy controls

260 during the acute phase of dengue infection (Fig. 1A). Stratification of groups according to disease severity

261 at discharge showed that SD patients had discrete but significantly lower levels of AnxA1 compared to

262 individuals with classic dengue (Fig. 1A).

\section{DENV infection reduces AnxA1 plasma levels in mice}

264 Since we identified reduced levels of AnxA1 in the plasma of dengue patients, we sought to investigate the 265 role of this pro-resolving mediator in dengue's pathogenesis. To examine how the AnxA1 pro-resolving 266 pathway operates in an immunologically intact system, we initially examined AnxA1 secretion during

267 DENV infection over time in an immunocompetent animal model of DENV infection. Although wild type

268 (WT) mice are more resistant to infection than immunocompromised animals (Shresta et al., 2004), these

269 animals were proven to be productively infected by DENV and are valid hosts to investigate the 270 mechanisms underlying DENV-induced vascular dysfunction (Chen, Hofman, Kung, Lin, \& Wu-Hsieh, 271 2007; St John, Rathore, et al., 2013; Syenina et al., 2015). In both DENV-infected BALB/c (Fig. 1B) and 272 C57BL/6 mice (Fig. 1C), there was a time-dependent decline in the concentration of plasma AnxA1 273 compared to mock-infected animals. These expression profiles motivated investigation on the role of the 274 AnxA1-FPR2/ALX pathway in dengue disease progression and severity. 

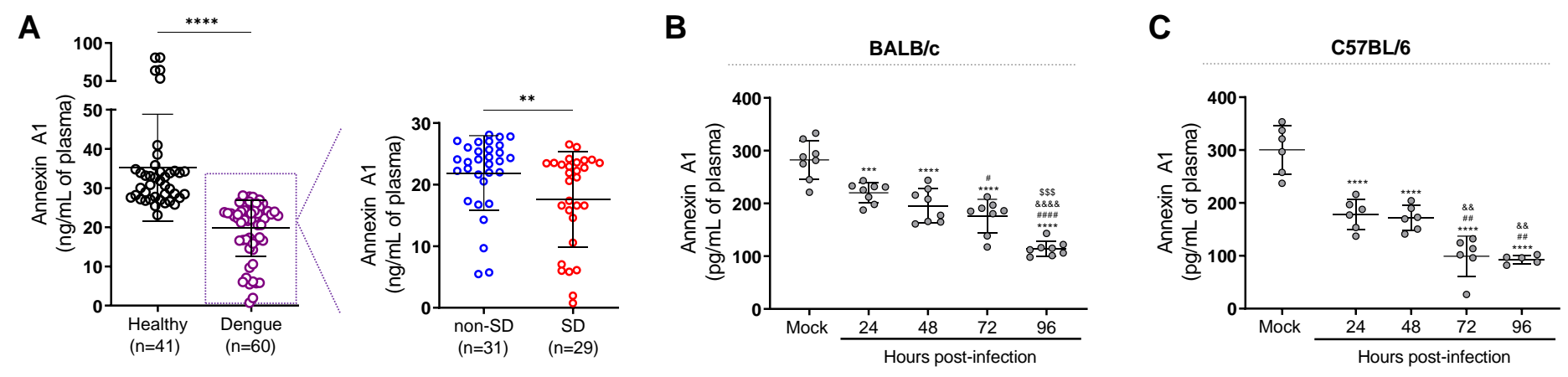

Figure 1. Annexin A1 levels are reduced in dengue patients and mice infected with DENV. (A) AnxA1

276

277

278

279

280

281

282

283

284

plasma levels in healthy and dengue patients. The latter group was stratified into non-severe dengue (non$\mathrm{SD}$, outpatients) and severe dengue (SD, inpatients) individuals. Each circle represents an individual participant, and horizontal bars represent mean values for AnxA1 (ng/mL of plasma), assayed by ELISA. ${ }^{* * * *} \mathrm{p}<0.0001,{ }^{*} \mathrm{p}<0.01$ by two-tailed Mann-Whitney test. (B) 5-week-old BALB/c $(\mathrm{n}=8)$ or (C) C57BL/6 WT (n=5-6) mice were intravenously injected with $1 \times 10^{6} \mathrm{PFU}$ of DENV-2 and culled in the indicated time points for plasma collection. AnxA1 plasma levels analysed by ELISA are shown.

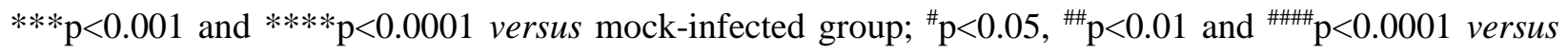
$24 \mathrm{~h}$-infected group; ${ }^{\&} \mathrm{p}<0.01$ and ${ }^{\& \& \& \&} \mathrm{p}<0.0001$ versus $48 \mathrm{~h}$-infected group; ${ }^{\$ \$} \mathrm{p}<0.001$ versus $72 \mathrm{~h}-$ infected group (one-way ANOVA followed by Tukey’s post hoc test).

Source data 1. Raw data for Figure 1A-C.

\section{Disruption of the AnxA1-FPR2/ALX pathway increases susceptibility to DENV infection}

We then conducted experiments in different animal strains to ascertain whether changes in AnxA1 expression could impact the dynamics of DENV infection (Fig. 2A). As previously described (St John, Rathore, et al., 2013), systemic infection of WT mice caused haematological and vascular changes consistent with the human disease, systemic MC activation, and inflammatory response (Fig. 2B-D). Disease parameters were aggravated in AnxA1 ${ }^{-/-}$animals compared with WT mice. In the absence of AnxA1, animals showed more severe and prolonged thrombocytopenia, haemoconcentration, and vascular permeability than WT mice (Fig. 2B-D), indicating a protective role of AnxA1 in dengue disease. These 
findings were similar in FPR2/ALX-depleted animals (Fig. 2G-I), suggesting that these effects are due to disruption of the AnxA1-FPR2/ALX pathway. Serum levels of MCPT-1 and CCL2 were increased in either AnxA1 and FPR2/ALX KO animals compared to their respective controls after infection (Fig. 2E,F,J,K). While parameters such as haematocrit and vascular leakage returned to basal levels $72 \mathrm{~h}$ after infection in WT animals, KO animals persisted with elevated levels, indicating a delay in resolving the host's haematological and immune response. Interestingly, AnxA1-depleted animals have preserved their ability to control virus spread, as splenic virus replication was similar to what was found in control animals (Fig. 2-figure supplement 1 ).

\section{AnxA1 agonism attenuates DENV infection manifestations}

Given the modulation of AnxA1 expression in DENV infected mice and the protective role of the AnxA1of the whole protein's effects in experimental inflammation (Sheikh \& Solito, 2018; Sugimoto, Vago, Teixeira, \& Sousa, 2016). The peptide therapy in WT animals (Fig. 3A) was effective after the first injection and protected against the major changes in haematological and immune markers as evident at $24 \mathrm{~h}$ and $48 \mathrm{~h}$ after DENV infection compared to mock-infected animals (Fig. 3B-F). Thrombocytopenia (Fig. 3B) and

311 provoked increased vascular permeability in both untreated and treated animals, but to a lesser extent when

312 animals were administrated daily with AnxA1 mimetic peptide (Fig. 3D). Of note, while increased 313 haematocrit levels and vascular leakage were observed as early as $24 \mathrm{~h}$ post-infection in vehicle-treated 314 mice, treatment with AnxA1 mimetic peptide delayed the onset of both disease manifestations (Fig. 3B-C).

315 Treatment with $\mathrm{Ac}_{2-26}$ also reduced the elevation in plasma MCPT-1 (Fig. 3E) and CCL2 (Fig. 3F) levels 316 compared to the untreated group. Notably, the improvements in disease symptoms appeared to be 317 independent of the splenic viral load (Fig. 3-figure supplement 1). 
318 When we applied the same treatment schedule to FPR2/ALX KO mice infected with DENV-2, Ac $2-26$ did

319 not affect the disease parameters under observation (Fig. 3G-K). Finally, the efficacy of $\mathrm{Ac}_{2-26}$ in these

320 settings allowed us to validate the data obtained with AnxA1 KO mice, as administration of AnxA1 peptide

321 to animals deficient in AnxA1 rescued the phenotype showed by this transgenic colony in dengue infection,

322 bringing values of haematological and immune parameters in line with those measured in untreated mice

323 (Fig. 3-figure supplement 2). Taken together, these results reveal the therapeutic potential of a pro-

324 resolving peptide in the context of dengue, supporting the hypothesis that it could be operative also in 325 settings with lower or absent AnxA1. 
A

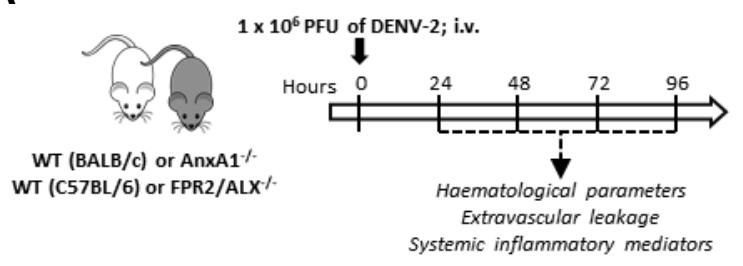

$\begin{array}{lll} & \circ & \text { WT } \\ & \Delta & \text { AnxA1 KO }\end{array}$

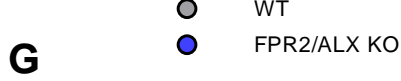
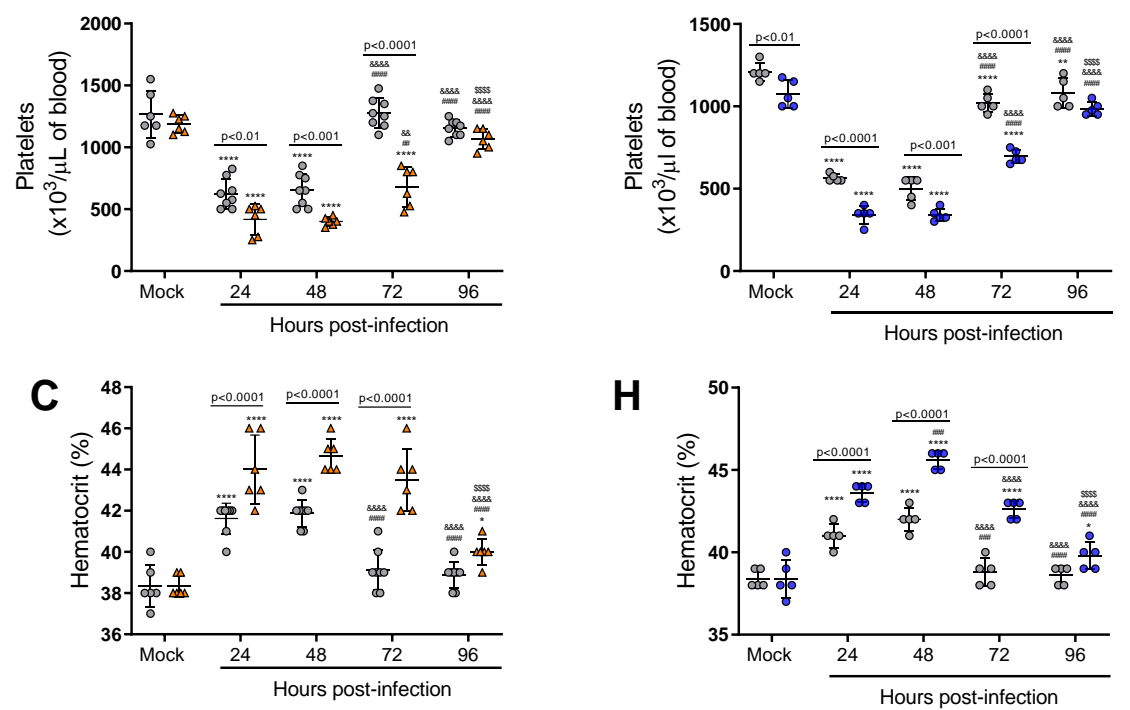

D
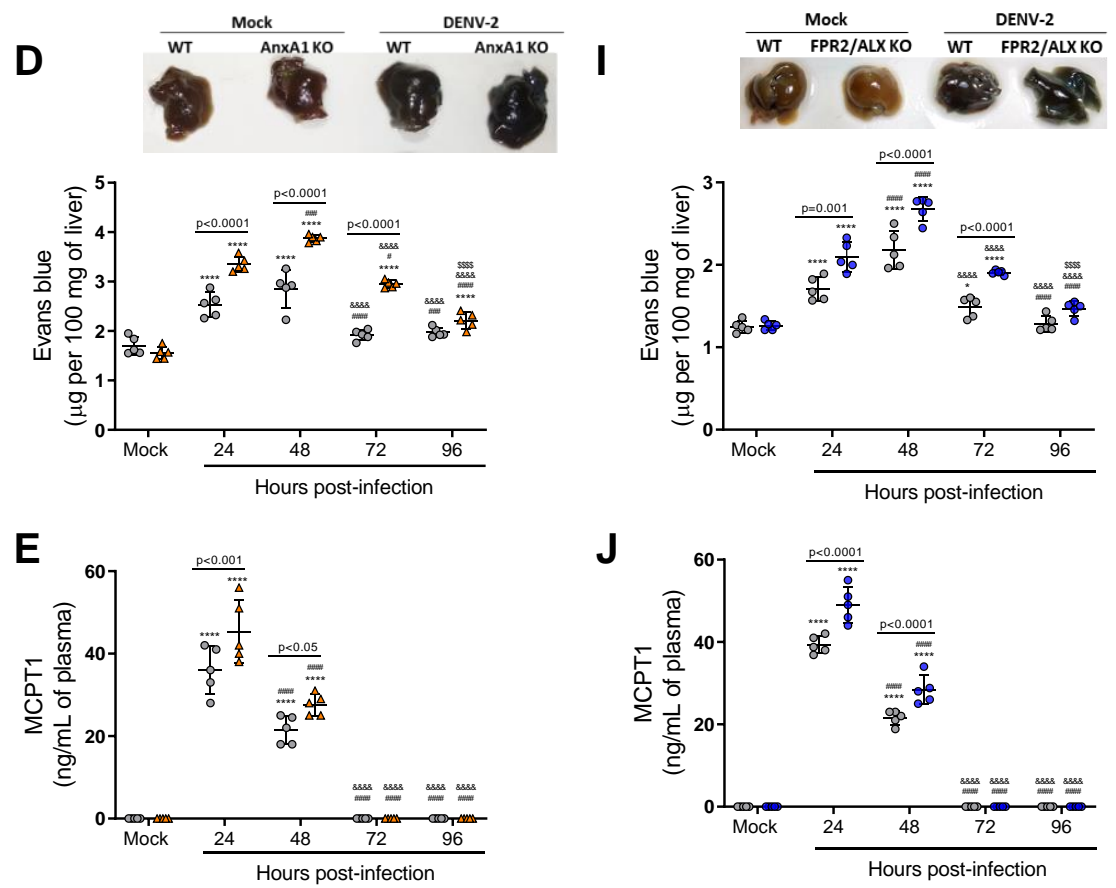

$\mathbf{J}$
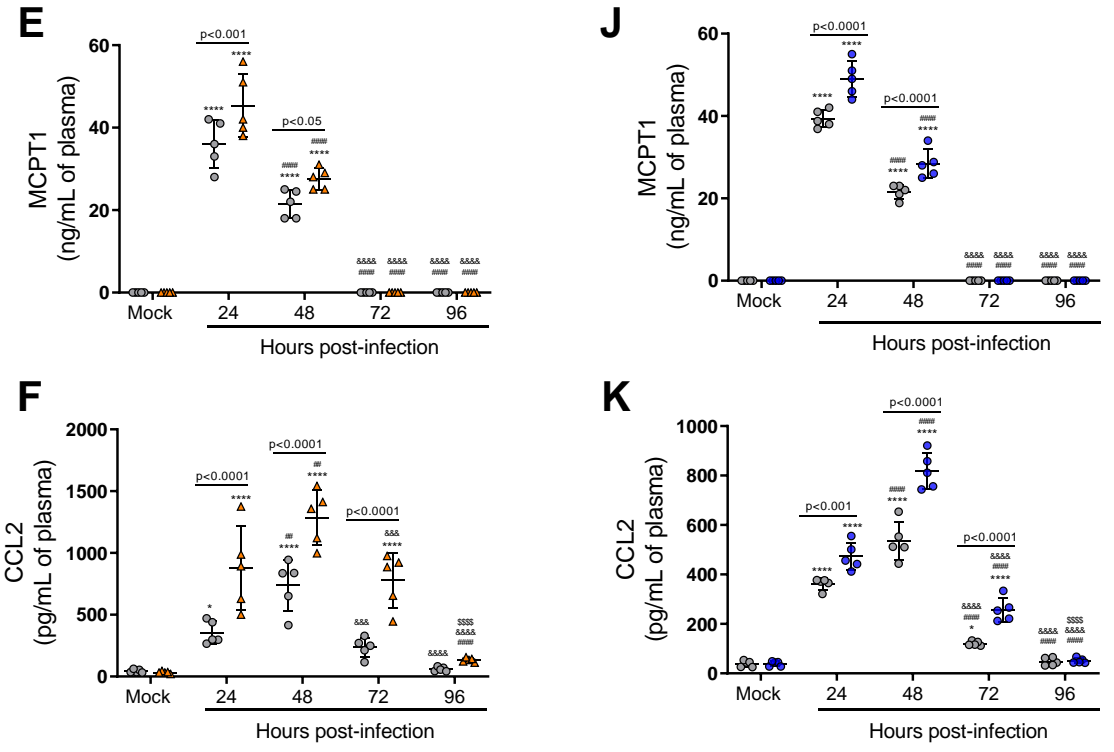
Figure 2. Mice are more susceptible to DENV-2 infection in the absence of Annexin A1 or its receptor FPR2/ALX. (A) Experimental design. (B-F) 5-week-old BALB/c WT and AnxA1 KO or (G-K) C57BL/6 and FPR2/ALX KO mice were intravenously inoculated with $1 \times 10^{6} \mathrm{PFU}$ DENV-2. Mice were culled in the indicated time points after infection, and blood and tissue were collected for the following analysis: (B,G) platelet counts, shown as the number of platelets $\times 10^{3} / \mu \mathrm{L}$ of blood; $(\mathbf{C}, \mathbf{H})$ haematocrit levels, shown as $\%$ volume occupied by red blood cells; (D,I) vascular leakage assay with Evans blue dye; concentrations of (E,J) MCPT1 and $(\mathbf{F}, \mathbf{K})$ CCL2 in plasma, quantified by ELISA and shown as quantity per mL of plasma. followed by Turkey's multiple comparison test: ${ }^{*} \mathrm{p}<0.05$, $* * \mathrm{p}<0.01$, $* * * \mathrm{p}<0.001$ and $* * * * \mathrm{p}<0.0001$ versus mock-infected group; ${ }^{\#} \mathrm{p}<0.05,{ }^{\# \#} \mathrm{p}<0.01,{ }^{\# \#} \mathrm{p}<0.001$ and ${ }^{\# \# \#} \mathrm{p}<0.0001$ versus $24 \mathrm{~h}-$ infected group; ${ }^{*} \mathrm{p}<0.05$, ANOVA followed by Sidak's multiple comparison test, as indicated in the graphs.

339 Source data 1: Raw data for Figure 2B-K.

340 Figure supplement 1 . Supplementary DENV virus RNA quantification results. 


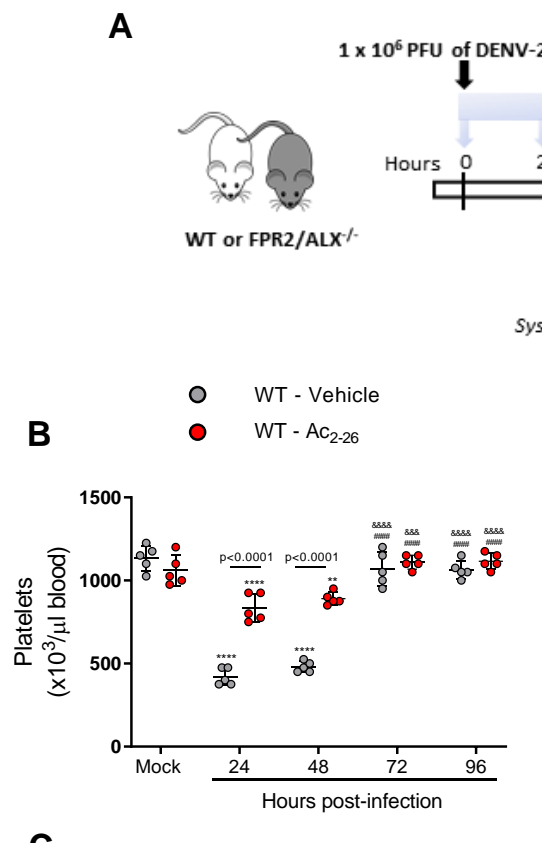

C

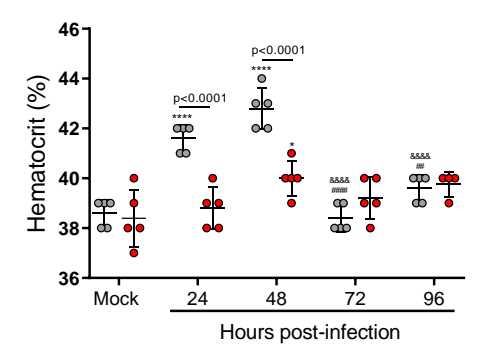

D

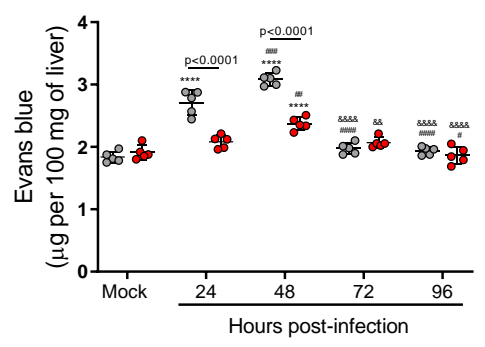

E

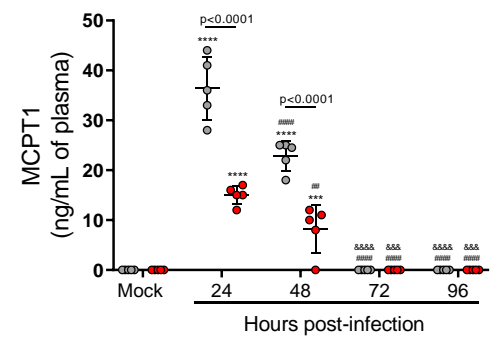

F

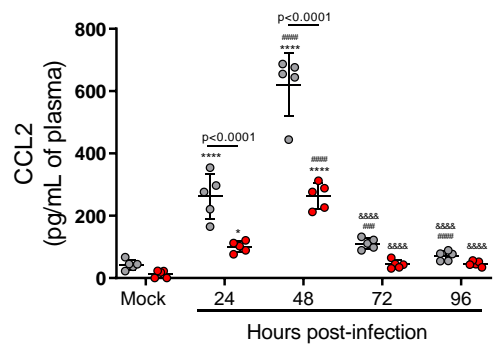

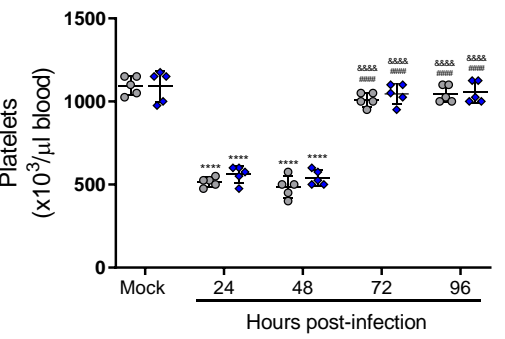

H

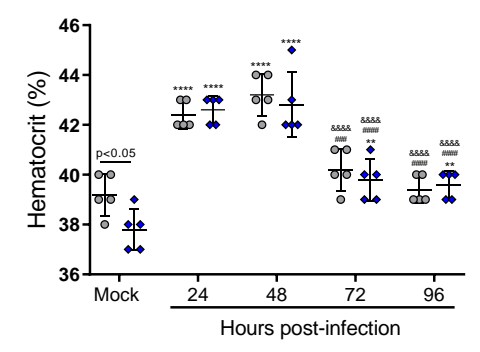

I

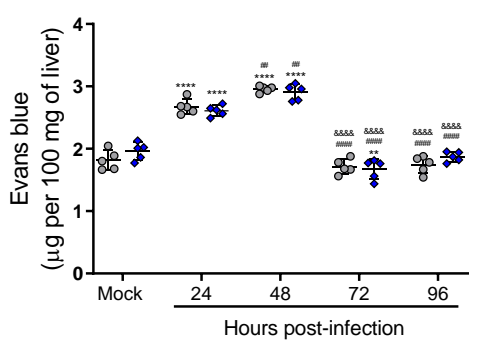

J

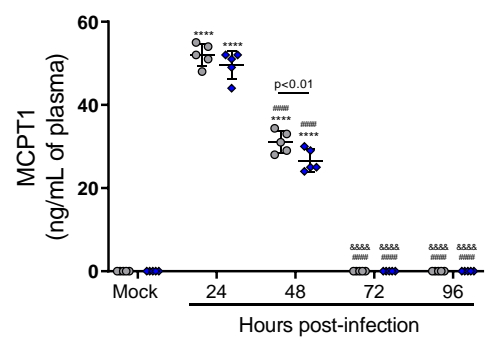

K

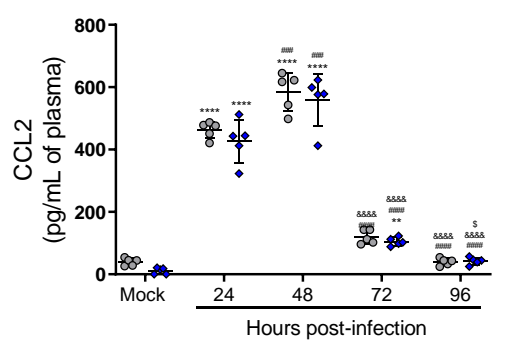



shown as quantity per $\mathrm{mL}$ of plasma. $\mathrm{N}=5$ animals per group, except for graph $\mathrm{C}$ where $\mathrm{n}=4-5$. Differences indicated in the graphs.

357 Figure supplement 1. Supplementary DENV virus RNA quantification results. mice challenged with DENV-2.

\section{Protective effects of $\mathrm{Ac}_{2-26}$ are independent of the control of viral loads and virus dissemination}

To establish whether $\mathrm{Ac}_{2-26}$ treatment could have a therapeutic benefit after the infection is established and if it affects viral loads, we applied a different experimental system (Fig. 4A), using mice bearing a null mutation for the IFN $\alpha / \beta$ receptor (A129 mice). These animals are highly susceptible to DENV infection and present severe macroscopic and microscopic alterations (Costa, Fagundes, Souza, \& Teixeira, 2013; Costa et al., 2014; Lam et al., 2017; Shresta et al., 2004). As seen for BALB/c and C57BL/6 strains, DENV- 
infected A129 mice showed reduced AnxA1 plasma levels over the course of infection, compared with mock-infected animals (Fig. 4B). While untreated A129 mice lost 10\% of their body weight from day two post-infection until the last time point analysed, treatment with $\mathrm{Ac}_{2-26}$ substantially delayed weight loss onset (Fig. 4C). The AnxA1 mimetic significantly reduced thrombocytopenia and haemoconcentration in response to DENV infection (Fig. 4D,E) and displayed efficacy on controlling innate immunity mediators,

371 with more significant effects in spleen values rather than plasma levels for CCL5 and IL-6 (Fig 4F,G).

372 Given the characteristic of early DENV infection in our model, it is expected that the blood level of these 373 markers would possibly not be altered by the analysed time point (5 d.p.i.). Infection of A129 mice induced 374 a degree of liver damage, monitored by elevated serum levels of ALT and high histopathological score (Fig.

375 4H-J). Remarkably, treatment with $\mathrm{Ac}_{2-26}$ attenuated liver injury caused by DENV, as indicated by reduced 376 histopathological score (Fig. 4H,I) and ALT transaminase levels (Fig. 4J). In this animal strain and using 377 this protocol, we could test the effects of $\mathrm{Ac}_{2-26}$ following infection with other DENV serotypes and 378 observed a significant reduction in haematological alterations, liver damage, and IL-6 production induced by either DENV-1, DENV-3, or DENV-4 (Fig. 5).

Finally, we investigated the potential impact of the $\mathrm{Ac}_{2-26}$ peptide on viral loads and virus dissemination.

381 A129 mice showed systemic viral burden on day five after DENV1-4 inoculation, with detectable viremia 382 and viral load in spleen and liver (Fig. 4K and Fig. 5F,G). Treatment with $\mathrm{Ac}_{2-26}$ did not affect systemic 383 viral burden, as untreated and treated mice showed similar viremia and viral loads. Treatment with $\mathrm{Ac}_{2-26}$ 384 caused only a slight reduction in viral loads in the spleen of mice infected with DENV-2 (Fig. 4K) and in 385 the plasma of animals inoculated with DENV-3 (Fig. 5F). These data indicate that the AnxA1 mimetic 386 positively impacts this severe dengue model, exerting little or no control on virus dissemination and viral 387 loads, thus genuinely regulating the host response. Moreover, we show that the efficacy of the AnxA1 peptide is not restricted to a single virus serotype. 
bioRxiv preprint doi: https://doi.org/10.1101/2021.11.02.466887; this version posted November 3, 2021. The copyright holder for this preprint (which was not certified by peer review) is the author/funder, who has granted bioRxiv a license to display the preprint in perpetuity. It is made available under aCC-BY 4.0 International license.

A

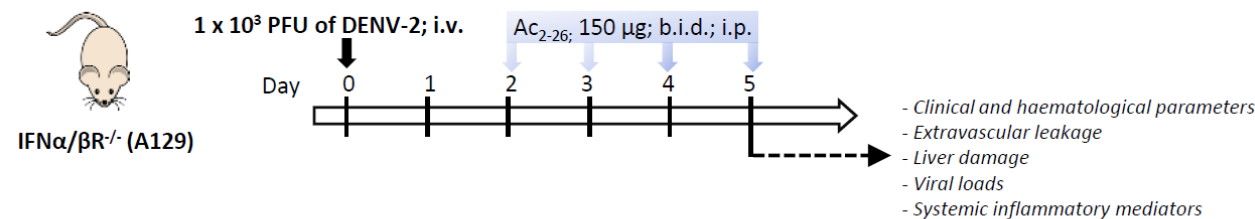

B

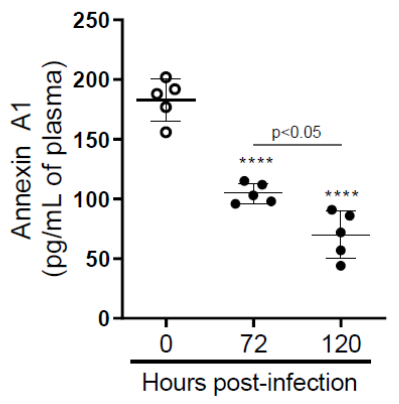

C

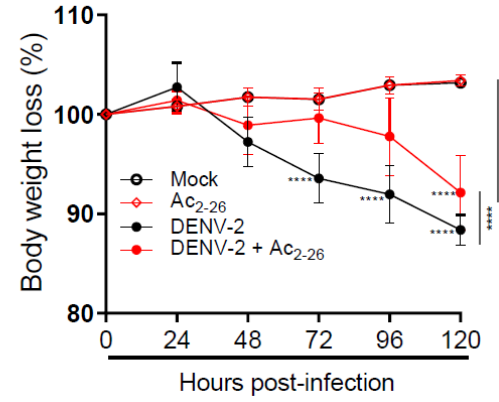

D

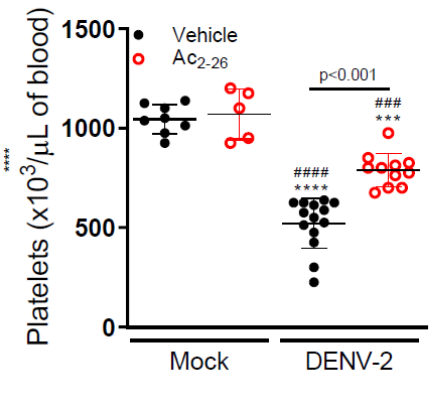

E

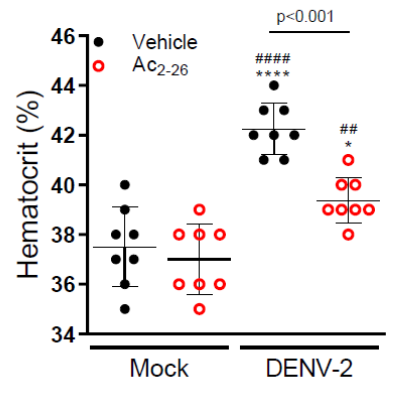

F

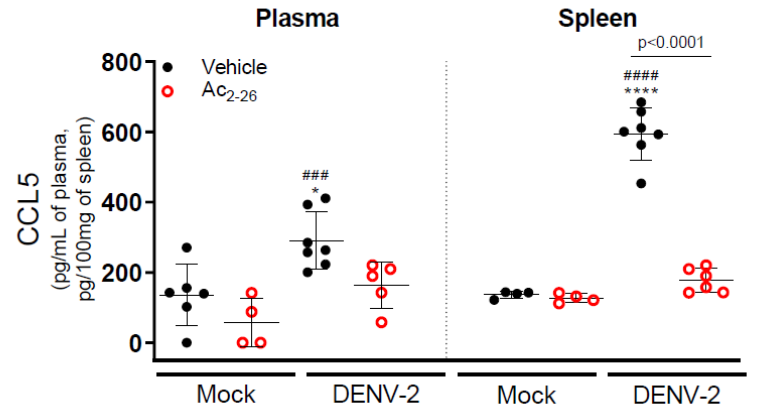

G

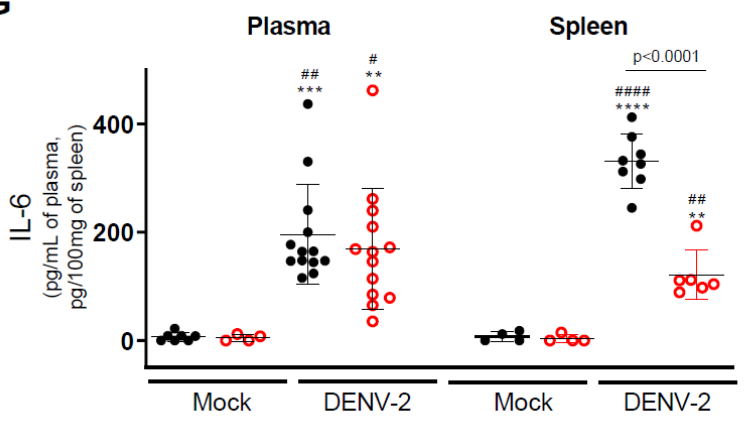

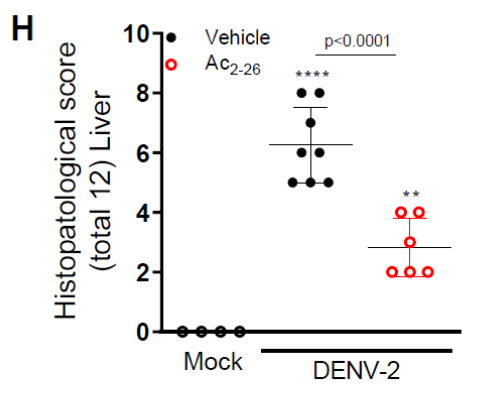

I
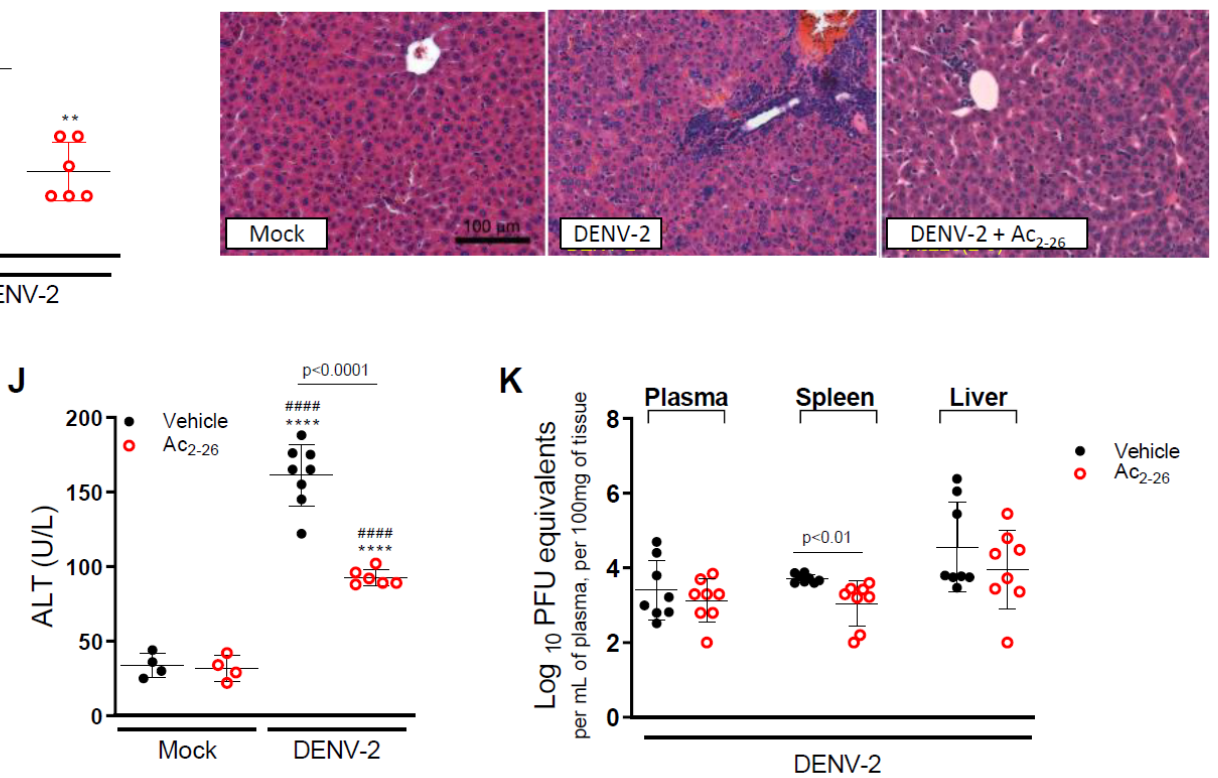

with $150 \mu$ g of $A_{2-26}$ by the intraperitoneal (i.p.) route. (B) Mice were culled in the indicated time points after infection, and plasma was collected for AnxA1 quantification by ELISA ( $n=5)$. (C) Bodyweight loss was assessed in the indicated time points and expressed as a percentage of initial body weight. Mock (open white circles), $\mathrm{Ac}_{2-26}$ (open red circles), and DENV-2-infected mice treated with vehicle (black closed circles) or $A_{2-26}$ (red closed circles); $\mathrm{n}=4-8$. Five days after infection, animals were culled, and blood and tissue collected for the following analysis: (D) platelet counts, shown as the number of platelets $\times 10^{3} / \mu \mathrm{L}$ of blood ( $\mathrm{n}=5-14)$; (E) haematocrit levels, shown as \% volume occupied by red blood cells $(\mathrm{n}=8)$; concentrations of (F) CCL5 and (G) IL-6 in plasma and spleen of mock and DENV-infected mice, treated or not with $\mathrm{Ac}_{2-26}$. Concentrations were assessed by ELISA and are shown as $\mathrm{pg} / \mathrm{mL}$ of plasma or as pg/100mg of the spleen (CCL2, n=4-7; IL-6, n=4-13). (H,I) Liver of control and DENV-2-infected mice, treated or not with the AnxA1 peptide, were collected, formalin-fixed, and processed into paraffin sections. eosin. Scale Bar, $100 \mu \mathrm{m}$. (J) Plasma ALT activity represented as units/L (H-J, n=4-8). (K) Viral loads recovered from plasma, spleen, and liver of infected mice treated or not with $\mathrm{Ac}_{2-26}$, examined by plaque assay in Vero cells. Results are shown as the log of PFU/mL of plasma or as the log of PFU/mg of spleen and liver $(\mathrm{n}=8)$. All results are expressed as mean (horizontal bars) \pm SD. In $\mathrm{B}$, differences over time and between treatments were compared by one-way ANOVA followed by Tukey's multiple comparisons test: $* * * * \mathrm{p}<0.0001$ versus mock-infected animals or comparing the different groups, as indicated in the graph. In C-J, data were analysed by one-way ANOVA followed by Tukey's multiple comparisons test: *p<0.05, ${ }^{* *} \mathrm{p}<0.01, * * * \mathrm{p}<0.001$ and $* * * * \mathrm{p}<0.0001$ versus mock-infected group; ${ }^{\#} \mathrm{p}<0.05,{ }^{\#} \mathrm{p}<0.01,{ }^{\# \#} \mathrm{p}<0.001$ and

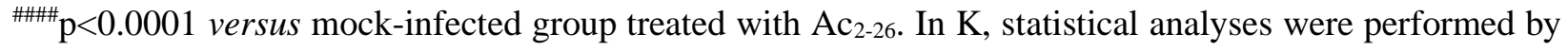
unpaired Student's t-tests for each organ. 
Figure 4 - Source data 1: Raw data for Figure 4B-H,J,K.
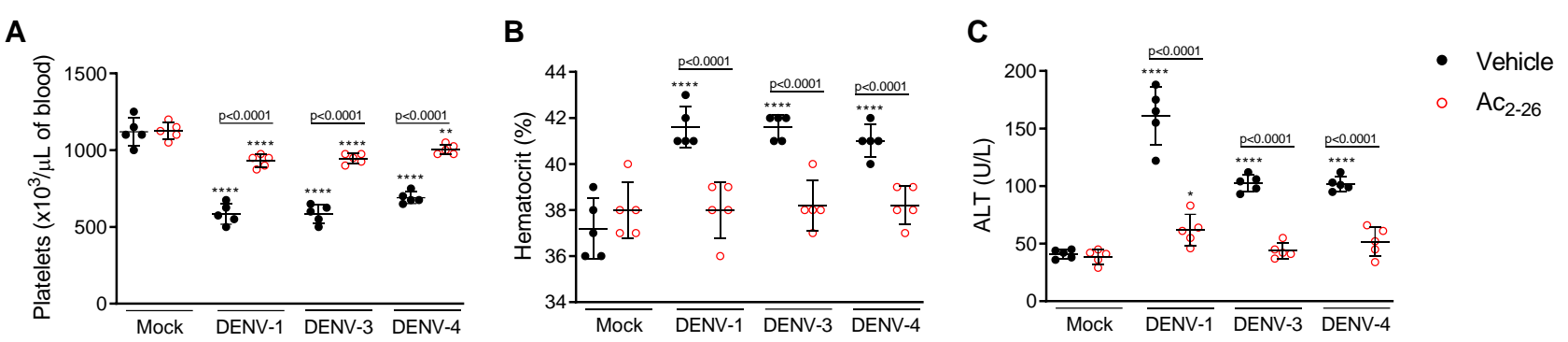

D

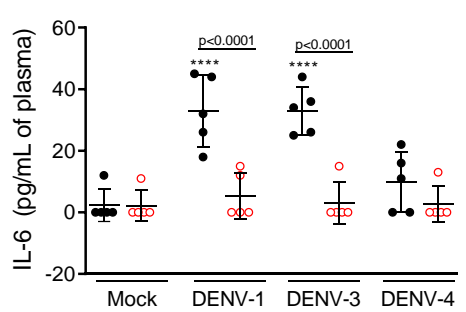

E

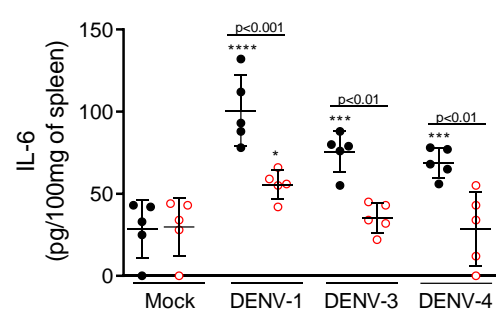

$\mathbf{F}$

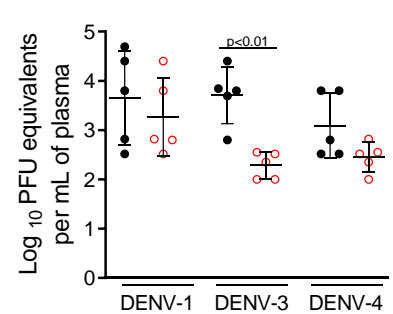

G

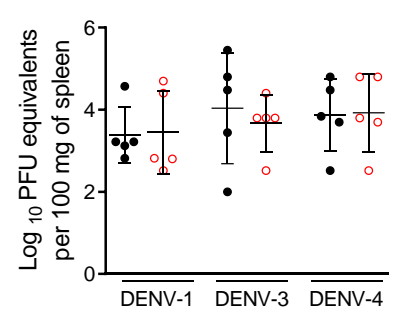

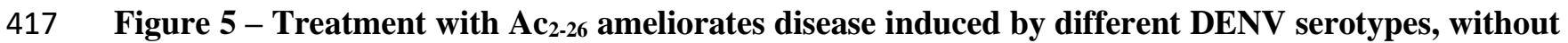
significantly impacting viral loads. 8-week-old A129 mice were mock-infected or inoculated with 4 x $10^{4}$ PFU of DENV-1, 1 x $10^{3}$ PFU of DENV-3 or $1 \times 10^{4}$ PFU of DENV-4 by the intravenous route ( $\left.\mathrm{n}=5\right)$. From day 2, mice were treated with vehicle (black closed circles) or $150 \mu \mathrm{g}$ of $\mathrm{Ac}_{2-26}$, i.p. twice a day (open red circles). Five days after infection, animals were culled, and blood and tissue were collected for the following analysis: (A) Platelet counts, shown as the number of platelets $\times 10^{3} / \mu \mathrm{L}$ of blood. (B) Haematocrit levels, 423 shown as \% volume occupied by red blood cells. (C) plasma ALT activity represented as 424 units/L. Concentrations of L-6 in (D) plasma and (E) spleen of mock- and DENV-infected mice, treated or 425 not with $\mathrm{Ac}_{2-26}$, assessed by ELISA. Concentrations are shown as $\mathrm{pg} / \mathrm{mL}$ of plasma or as $\mathrm{pg} / 100 \mathrm{mg}$ of the 426 spleen. Viral loads recovered from (F) plasma and (G) spleen of mice infected with the three serotypes of 427 DENV and treated or not with $\mathrm{Ac}_{2-26}$, evaluated by plaque assay in Vero cells. Results are shown as the log 428 of PFU/mL of plasma or as the log of PFU/mg of spleen and liver. In A-E, data were analysed by two-way 429 ANOVA followed by Dunnett's $\left({ }^{*} \mathrm{p}<0.05,{ }^{* *} \mathrm{p}<0.01,{ }^{* * *} \mathrm{p}<0.001\right.$ and $* * * * \mathrm{p}<0.0001$ versus mock-infected 430 group) or Śídák's (statistical differences between infected mice treated with vehicle or $\mathrm{Ac}_{2-26}$, as indicated in the graphs) multiple comparison test. In F-G, statistical analysis was performed by two-way ANOVA 

${ }_{26}$ are indicated in the graphs. Horizontal bars represent mean values.

434 Figure 5 - Source data 1: Raw data for Figure 5A-G.

\section{$A_{2-26}$ prevents mast cell degranulation evoked by DENV}

There is compelling evidence that MC degranulation contributes to DENV-induced vascular leakage and

437 disease severity (St John, Rathore, et al., 2013; Syenina et al., 2015; Tissera et al., 2017). In line with this,

438 we report increased MCPT-1 levels in the plasma of DENV-infected mice (Figures 2E,J; 3E,J and Fig 3-

439 figure supplement 2E). We hypothesised that the AnxA1 peptide could, at least in part, exert its protective 440 effects by preventing MC degranulation. To test this hypothesis, we took advantage of in vivo and in vitro systems. We first analysed MCs from hind paw histological sections of WT mice pretreated with vehicle or AnxA1 mimetic peptide and infected with DENV (Fig. 6A). Both animals treated locally or systemically had decreased MC degranulation in comparison with control mice. To confirm a direct effect of the peptide in $\mathrm{MC}$ function, we cultured BMMCs and added $\mathrm{Ac}_{2-26}$ before challenging cells with DENV-2. We then assessed BMMC degranulation in response to DENV-2 by a standard $\beta$-hexosaminidase assay. Ac $2-26$ inhibited $\beta$-hexosaminidase release evoked by DENV-2 in a concentration-dependent manner, with 40\%

447 reduction in release at $100 \mu \mathrm{M} \mathrm{Ac} \mathrm{c}_{2-26}$ (Fig 6B). To confirm this observation, we performed a TEM assay. maturation with cytoplasmic granules accumulating focal, rounded aggregates of electron-dense material

450 (Fig. 6C) (Combs, 1971; Dvorak et al., 1982). Ultrastructural evidence of degranulation was identified in 451 BMMC cultured with DENV (Fig. 6D,F), in which cells showed enlarged cytoplasmic granules with 452 reduced electron density and granule-granule fusion events - all morphological changes indicative of 453 content release (Carmo et al., 2016). These features were consistently reduced when infected cells were 454 pretreated with $100 \mu \mathrm{M} \mathrm{Ac}_{2-26}$ peptide (Fig. 6E). Quantification of the morphological changes in granules 455 showed that $\mathrm{Ac}_{2-26}$ prevented the increase in granule diameters caused by DENV (Fig. 6G). In addition, 
A

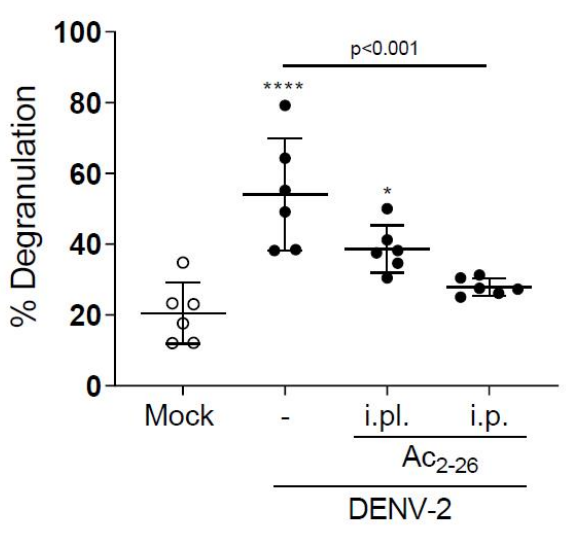

B

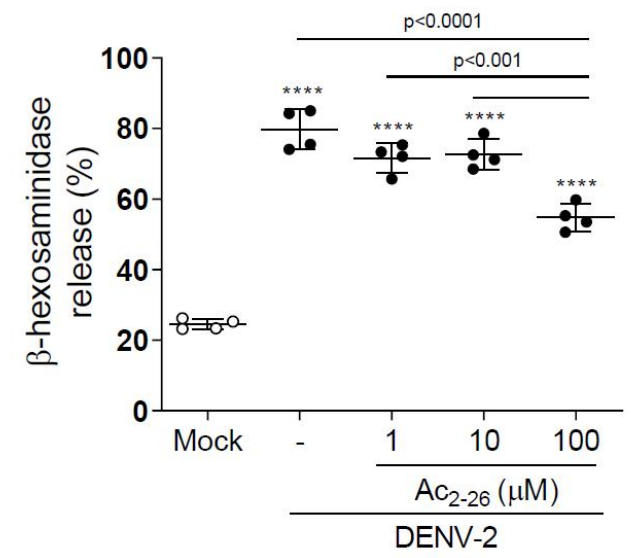

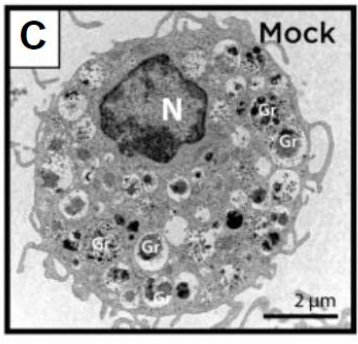

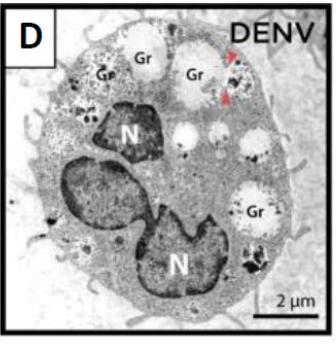

G

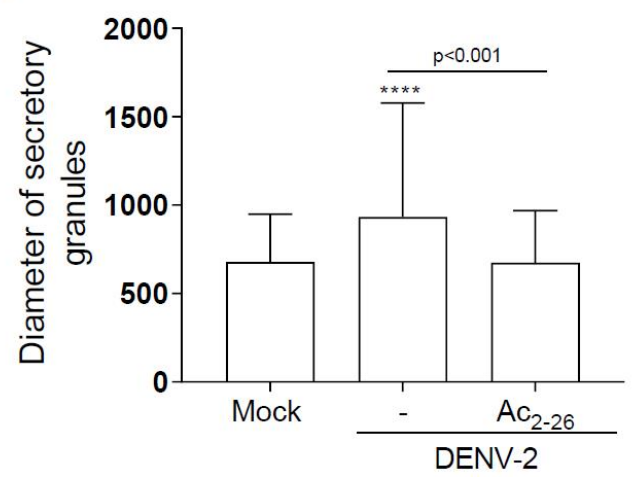

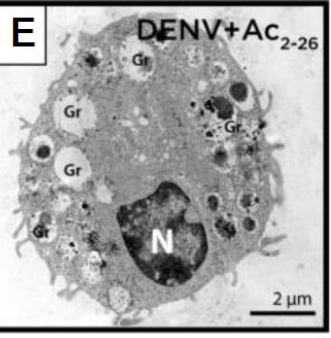

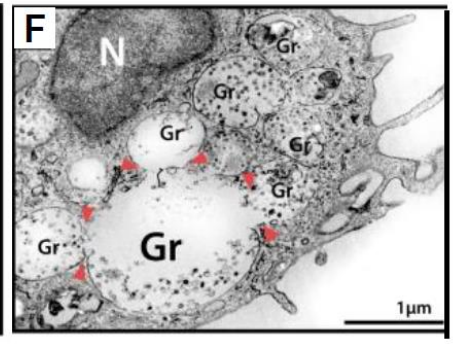

$\mathrm{H}$

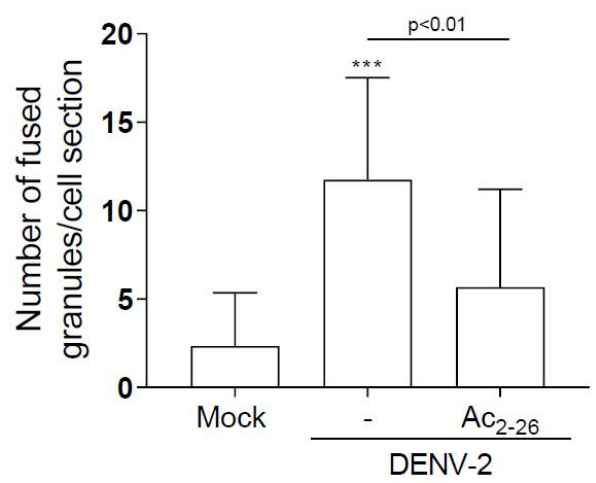

461 Figure 6 -Ac $\mathbf{A c}_{2-26}$ diminishes mast cell degranulation induced by DENV both in vivo and in vitro. (A)

462 WT mice were treated with $\mathrm{Ac}_{2-26}$ via footpad injections (i.pl.) or i.p and infected with DENV-2 via footpad 
injections ( $\mathrm{n}=6)$. Three hours later, mice were euthanised and had their hind paws removed to analyse MC degranulation. (B) $\beta$-hexosaminidase activity of mouse bone marrow-derived mast cells (BMMC),

465 pretreated or not with increasing concentrations of $\mathrm{Ac}_{2-26}$ for $1 \mathrm{~h}$, and stimulated with DENV-2 (MOI of 1)

466 for an extra $30 \mathrm{~min}(\mathrm{n}=4)$. The data show the percentage release of cellular $\beta$-hexosaminidase into the

467 medium and represent two independent experiments. (C-H) Transmission electron microscopy (TEM) of

468 BMMC, pretreated or not with $\mathrm{Ac}_{2-26} 100 \mu \mathrm{M}$ for $1 \mathrm{~h}$ and challenged with DENV-2 (MOI of 1) for an extra

46930 min. (C) Mock-stimulated BMMC show maturing cytoplasmic granules accumulating electron-dense

470 material. (D) Granule enlargement, emptying, and fusion are observed in response to DENV-2 infection.

471 (E) $\mathrm{Ac}_{2-26}$ peptide treatment reduces morphological features of secretion evoked by DENV infection. Scale

472 bar, $2 \mu \mathrm{m}$. (F) Granule fusions (arrowhead) in untreated DENV-infected BMMC are seen in higher

473 magnification (scale bar, $1 \mu \mathrm{m}$ ). Significant increases in $(\mathbf{G})$ granule diameters and $(\mathbf{H})$ number of fused

474 granules occur after stimulation with DENV-2 compared to both mock-stimulated cells and DENV-

475 stimulated cells treated with $\mathrm{Ac}_{2-26}$ peptide. In G, bars represent the mean diameter \pm SD of 372,360 , and

476384 secretory granules analysed in the mock, DENV-2 and DENV-2+Ac 2-26 groups, respectively. In $\mathrm{H}$, bars

477 represent the mean number of fused granules \pm SD analysed in 15 sections per group. A,B,H, statistical

478 analysis was performed by one-way ANOVA followed by Tukey's multiple comparisons test: ***p<0.001

479 and $* * * * \mathrm{p}<0.0001$ compared to mock-infected cells, or as depicted on the graphs. $\mathrm{G}$, data analysed by

480 Kruskal Wallis followed by Dunn multiple comparison test. Gr, secretory granules; N, nucleus.

481 Figure 6 - Source data 1: Raw data for Figure 6A,B,G,H.

482 Figure 6-figure supplement 1. Supplementary representative images of the footpad sections used for the 483 quantitative analysis showed in Figure 6A.

\section{DISCUSSION}

485 We present evidence that an inadequate engagement of the resolution circuit AnxA1-FPR2/ALX may 486 contribute to dengue infection's pathogenesis with particular relevance for the cohort of patients affected 
by the most severe forms of the disease. By exploring resolution biology as a novel approach in dengue disease, both with respect to etiopathogenesis and pharmacological opportunity, we have identified that: (i) AnxA1 is downregulated in the plasma of dengue patients in comparison to healthy individuals and in DENV-infected mice in comparison to non-infected animals; (ii) depletion of the AnxA1-FPR2/ALX pathway aggravates clinical signs and enhances MC activation associated to DENV infection, indicating a nonredundant role for this resolution pathway in the pathogenesis of dengue disease; (iii) pharmacological treatment of mice with an FPR2/ALX agonistic peptide produced beneficial effects during DENV infection; (iv) AnxA1 mimetic peptide has direct inhibitory effects on MC degranulation induced by DENV while (v) it does not seem to control viral load and virus dissemination significantly. 'failure' in resolving mechanisms (Schett \& Neurath, 2018; Tabas \& Glass, 2013). The severity and lethality of several infectious diseases, like dengue and the flu, frequently arise from an excessive host response, characterised by an uncontrolled release of pro-inflammatory cytokines leading to over-exuberant immune activation (Costa et al., 2013; St John, Abraham, \& Gubler, 2013). Inflammation is physiologically balanced by resolution circuits, such as those centred on AnxA1 and lipid mediators (e.g. lipoxins, resolvins, protectins and maresins) that drive termination of inflammatory response yet helping the host to 504 deal with the infective agent (Basil \& Levy, 2016). In line with this, a growing body of evidence indicates 505 that pro-resolving mediators are regulated during infection, contributing to the control and resolution of 506 experimental and human infectious diseases (Abdulnour et al., 2016; Basil \& Levy, 2016; Chiang et al., 507 2012; Frediani et al., 2014; Oliveira et al., 2017; Shirey et al., 2014). On the other hand, dysregulation in 508 the production and/or action of pro-resolving mediators might contribute to the pathogenesis of sterile (Eke 509 Gungor et al., 2014; Fredman et al., 2016; Murri et al., 2013; Sena et al., 2013; Thul et al., 2017; Vong et al., 2012) and infectious (Cilloniz et al., 2010; Colas et al., 2019; Molas et al., 2020; Morita et al., 2013) 
of AnxA1 in the context of viral infections has been less investigated, and clinical data are scarce (Arora et pathways during self-resolving infections (Cilloniz et al., 2010; Colas et al., 2019; Molas et al., 2020; Morita et al., 2013), we queried whether such alterations could also be occurring in dengue disease. Focus was given to the pro-resolving protein AnxA1 and its cognate receptor FPR2/ALX, a pathway that has been

517 shown to exert a degree of protection in experimental tuberculosis (Tzelepis et al., 2015; Vanessa et al., 518 2015), sepsis (Amilcar S. Damazo et al., 2005; Gobbetti et al., 2014), pneumococcal pneumonia (Machado et al., 2020; Tavares et al., 2016) and influenza (Schloer et al., 2019). Our data indicate that in addition to the already described early induction of an inflammatory response that may be harmful instead of protective, DENV infection is also characterised by sustained downregulation of molecular components of the AnxA1 pathway. The drop in circulating AnxA1 below basal levels observed in dengue patients in this study, especially in severe dengue, suggests that the pathogenesis and severity of the disease might be associated with a failure to engage mechanisms involved in endogenous anti-inflammatory signals and its resolution, such as those centred on AnxA1. Furthermore, we have identified a protective role for the AnxA1-FPR2/ALX pathway in DENV infection, as animals presented heightened signs of disease in the

527 absence of either ligand or receptor, compared to WT mice. In line with integrated pro-resolving properties of resolution circuits, AnxA1 and FPR2/ALX KO mice displayed diverse uncontrolled responses leading to a higher degree of susceptibility to DENV-2 infection. Markers of MC degranulation and systemic inflammation were elevated in transgenic mice compared to WT counterparts. Similarly, these genetically manipulated animals presented enhanced haematological alterations in our model of experimental dengue.

532 Infections are currently treated by drugs that target pathogens or inhibit their growth. In some infectious 533 diseases, blocking inflammation pathways may be beneficial. While this approach might be successful in some infections, excessive inhibition of the immune response can also be associated with immunosuppression and increased mortality, as observed in septic patients (Carlet, Payen, \& Opal, 2020). 
537 hampering its ability to deal with the infection. Indeed, pro-resolving receptor agonists' exogenous 538 administration has proven benefits in experimental infectious settings, including bacterial pneumonia 539 (Abdulnour et al., 2016; Machado et al., 2020) and influenza (Morita et al., 2013; Ramon et al., 2014; 540 Schloer et al., 2019). In the present work, we provide proof-of-principle that a pro-resolving tool, the $\mathrm{Ac}_{2}-$ 54126 peptide, can ameliorate clinical disease and reduce circulating inflammatory mediators in an FPR2/ALX542 dependent manner. The AnxA1 peptide was effective even when administered from day two after the 543 infection onset. In addition, in our experimental models, viral load was seemingly unaffected by $\mathrm{Ac}_{2-26}$ 544 treatment, supporting a protective effect independent of viral infectivity. contributes to the immunopathology of dengue. For instance, MC activation in response to DENV plays an essential role in DENV-induced vascular pathology, particularly concerning the plasma leakage that causes hypovolemic shock in severe dengue (St John, Rathore, et al., 2013; Syenina et al., 2015). This is supported by a correlation between circulating MCPT-1 levels and disease severity in humans (A. P. S. Rathore et al., 2020; Tissera et al., 2017). It has been recently described that AnxA1 acts as an endogenous modulator of MC degranulation in response to IgE/anti-IgE or compound 48/80, suggesting that this pro-resolving axis act as a brake in MC degranulation (Sinniah et al., 2016; Yazid et al., 2013). The present study confirmed that dengue disease is associated with increased plasma levels of MCPT-1 and identified enhanced secretion in animals lacking AnxA1 or FPR2/ALX. Herein, we have identified the ability of $\mathrm{Ac}_{2-26}$ to reduce DENV-

555 induced MC degranulation dose-dependently, a mechanism that might underpin the reduced MCPT-1

556 secretion and vascular dysfunction observed in AnxA1 peptide-treated animals. Together, in vivo and in 557 vitro evidence suggest that $\mathrm{Ac}_{2-26}$, at least in part, acts by attenuating $\mathrm{MC}$ degranulation evoked by DENV, 558 protecting the host against vascular dysfunction associated with the disease. This mode of action points to 559 this pathway as a relevant potential target for DENV infection treatment, as MCs are resistant to infection 560 but play a key role in dengue pathogenesis (Beatty et al., 2015; Modhiran et al., 2015; St John, Rathore, et 561 al., 2013). 
562 Our results indicate that altered levels of the pro-resolving mediator AnxA1 are of pathological relevance

563 in dengue disease. We show that inadequate engagement of resolution circuits contributes to the excessive

564 inflammation observed in severe DENV infection. In addition, we provide evidence for the benefits of

565 pharmacological therapy directed to modulating host immune responses in the absence of a direct antiviral

566 effect. These findings point to a direction for future research on applying FPR2/ALX agonists as a

567 therapeutic target for dengue disease.

\section{CONTRIBUTORS}

569 VVC, MAS, DGS, HCS, MP, and MMT conceived and planned the experiments. VVC, MAS, JH, JC, TG,

570 GOLR, JLB, IP, CEML, and TM carried out the experiments. CMQJ performed and provided expertise for

571 the histopathological analysis. VVC, MAS and CSB took the lead in writing the manuscript. MAS, VVC,

572 MVMA, and JH planned and executed in vitro experiments. KB and RCNM performed, analysed, and

573 interpreted TEM. MHGP and HCS recruited patients, performed the clinical evaluation, and collected the

574 human samples. VVC, MAS, and LPS performed and analysed the anti-Annexin A1 ELISA assays. All

575 authors provided critical feedback and helped shape the research, analysis, and manuscript.

\section{DECLARATION OF INTERESTS}

577 MP is on the Scientific Advisory Board of ResoTher Pharma AS, which is interested in developing Annexin

578 A1-derived peptides for cardiovascular settings. The remaining authors declare that the research was

579 conducted without any commercial or financial relationships that could be construed as a potential conflict

580 of interest.

\section{ACKNOWLEDGEMENTS}

582 We would like to thank Ilma Marçal, Tania Colina, Frankcineia Assis, and Gilvania Santos for technical

583 support. We also would like to thank Prof. Eng Eong Ooi from Duke NUS Medical School in Singapore 
584 for providing the DENV strains used in mouse experiments. This work received financial support from the

585 Fapemig Hospedeiro em Dengue project, the Medical Research Council in the United Kingdom (Newton

586 project MR/No17544/1), the National Institute of Science and Technology in Dengue and Host-

587 microorganism Interaction (INCT dengue), a program funded by The Brazilian National Science Council

588 (CNPq, Brazil) and Minas Gerais Foundation for Science (FAPEMIG, Brazil). JC and MP are also funded

589 by the William Harvey Research Foundation. This study was financed in part by the Coordenação de

590 Aperfeiçoamento de Pessoal de Nível Superior (CAPES, Brazil) - Finance Code 001. We also thank

591 L'Oréal-UNESCO-ABC "Para Mulheres na Ciência” prize granted to VVC.

592 DATA SHARING

593 All data has been included in the manuscript, and source data files have been provided for Figures 1-6.

594 The online version of this article will include the following source code and supplementary files:

595 Figure 1 - Source data 1: Raw data for Figure 1A-C.

596 Figure 2 - Source data 1: Raw data for Figure 2B-K.

$597 \quad$ Figure 3 - Source data 1: Raw data for Figure 3B-K.

$598 \quad$ Figure 4 - Source data 1: Raw data for Figure 4B-H,J,K.

$599 \quad$ Figure 5 - Source data 1: Raw data for Figure 5A-G.

600 Figure 6 - Source data 1: Raw data for Figure 6A,B,G,H.

601 Figure 2-figure supplement. Supplementary DENV virus RNA quantification results.

602 Figure 3-figure supplement 1. Supplementary DENV virus RNA quantification results.

603 Figure 3-figure supplement 2. Supplementary results showing the protective effect of $\mathrm{Ac}_{2-26}$ peptide in 604 AnxA1 KO mice challenged with DENV-2.

605 Figure 6-figure supplement 1. Supplementary representative images of the footpad sections used for the 606 quantitative analysis showed in Figure 6A. 
bioRxiv preprint doi: https://doi.org/10.1101/2021.11.02.466887; this version posted November 3, 2021. The copyright holder for this preprint (which was not certified by peer review) is the author/funder, who has granted bioRxiv a license to display the preprint in perpetuity. It is made available under aCC-BY 4.0 International license.

607 Supplementary Table 1: oligo primers and probes used in clinical samples. 


\section{REFERENCES}

609

610

611

612

613

614

615

616

617

618

619

620

621

622

623

624

625

626

627

628

629

630

631

632

633

634

635

636

637

638

639

640

641

642

643

644

645

646

647

648

649

650

651

652

Abdulnour, R. E., Sham, H. P., Douda, D. N., Colas, R. A., Dalli, J., Bai, Y., . . Levy, B. D. (2016). Aspirintriggered resolvin $\mathrm{D} 1$ is produced during self-resolving gram-negative bacterial pneumonia and regulates host immune responses for the resolution of lung inflammation. Mucosal Immunol, 9(5), 1278-1287. doi:10.1038/mi.2015.129

Andrade, M. V., Iwaki, S., Ropert, C., Gazzinelli, R. T., Cunha-Melo, J. R., \& Beaven, M. A. (2011). Amplification of cytokine production through synergistic activation of NFAT and AP-1 following stimulation of mast cells with antigen and IL-33. Eur J Immunol, 41(3), 760-772. doi:10.1002/eji.201040718

Arora, S., Lim, W., Bist, P., Perumalsamy, R., Lukman, H. M., Li, F., . . Lim, L. H. (2016). Influenza A virus enhances its propagation through the modulation of Annexin-A1 dependent endosomal trafficking and apoptosis. Cell Death Differ, 23(7), 1243-1256. doi:10.1038/cdd.2016.19

Basil, M. C., \& Levy, B. D. (2016). Specialised pro-resolving mediators: endogenous regulators of infection and inflammation. Nat Rev Immunol, 16(1), 51-67. doi:10.1038/nri.2015.4

Beatty, P. R., Puerta-Guardo, H., Killingbeck, S. S., Glasner, D. R., Hopkins, K., \& Harris, E. (2015). Dengue virus NS1 triggers endothelial permeability and vascular leak that is prevented by NS1 vaccination. Sci Transl Med, 7(304), 304ra141. doi:10.1126/scitranslmed.aaa3787

Bhatt, S., Gething, P. W., Brady, O. J., Messina, J. P., Farlow, A. W., Moyes, C. L., . . Hay, S. I. (2013). The global distribution and burden of dengue. Nature, 496(7446), 504-507. doi:10.1038/nature12060

Carlet, J., Payen, D., \& Opal, S. M. (2020). Steroids for sepsis and ARDS: this eternal controversy remains with COVID-19. Lancet, 396(10259), E61-E62. doi:10.1016/S0140-6736(20)32132-2

Carmo, L. A. S., Bonjour, K., Ueki, S., Neves, J. S., Liu, L., Spencer, L. A., . . Melo, R. C. N. (2016). CD63 is tightly associated with intracellular, secretory events chaperoning piecemeal degranulation and compound exocytosis in human eosinophils. J Leukoc Biol, 100(2), 391-401. doi:10.1189/jlb.3A1015-480R

Chen, H. C., Hofman, F. M., Kung, J. T., Lin, Y. D., \& Wu-Hsieh, B. A. (2007). Both virus and tumor necrosis factor alpha are critical for endothelium damage in a mouse model of dengue virus-induced hemorrhage. J Virol, 81(11), 5518-5526. doi:10.1128/JVI.02575-06

Chiang, N., Fredman, G., Backhed, F., Oh, S. F., Vickery, T., Schmidt, B. A., \& Serhan, C. N. (2012). Infection regulates pro-resolving mediators that lower antibiotic requirements. Nature, 484(7395), 524528. doi:10.1038/nature11042

Cilloniz, C., Pantin-Jackwood, M. J., Ni, C., Goodman, A. G., Peng, X., Proll, S. C., . . Katze, M. G. (2010). Lethal dissemination of $\mathrm{H} 5 \mathrm{~N} 1$ influenza virus is associated with dysregulation of inflammation and lipoxin signaling in a mouse model of infection. J Virol, 84(15), 7613-7624. doi:10.1128/JVI.0055310

Colas, R. A., Nhat, L. T. H., Thuong, N. T. T., Gomez, E. A., Ly, L., Thanh, H. H., . . Dalli, J. (2019). Proresolving mediator profiles in cerebrospinal fluid are linked with disease severity and outcome in adults with tuberculous meningitis. FASEB J, 33(11), 13028-13039. doi:10.1096/fj.201901590R

Combs, J. W. (1971). An electron microscope study of mouse mast cells arising in vivo and in vitro. J Cell Biol, 48(3), 676-684. doi:10.1083/jcb.48.3.676

Costa, V. V., Fagundes, C. T., Souza, D. G., \& Teixeira, M. M. (2013). Inflammatory and innate immune responses in dengue infection: protection versus disease induction. Am J Pathol, 182(6), 19501961. doi:10.1016/j.ajpath.2013.02.027

Costa, V. V., Fagundes, C. T., Valadao, D. F., Avila, T. V., Cisalpino, D., Rocha, R. F., ... Souza, D. G. (2014). Subversion of early innate antiviral responses during antibody-dependent enhancement of 
Dengue virus infection induces severe disease in immunocompetent mice. Med Microbiol Immunol, 203(4), 231-250. doi:10.1007/s00430-014-0334-5

Costa, V. V., Fagundes, C. T., Valadao, D. F., Cisalpino, D., Dias, A. C., Silveira, K. D., . . Souza, D. G. (2012). A model of DENV-3 infection that recapitulates severe disease and highlights the importance of IFN-gamma in host resistance to infection. PLoS Negl Trop Dis, 6(5), e1663. doi:10.1371/journal.pntd.0001663

Damazo, A. S., Yona, S., D'Acquisto, F., Flower, R. J., Oliani, S. M., \& Perretti, M. (2005). Critical Protective Role for Annexin 1 Gene Expression in the Endotoxemic Murine Microcirculation. The American Journal of Pathology, 166(6), 1607-1617. doi:10.1016/s0002-9440(10)62471-6

Damazo, A. S., Yona, S., Flower, R. J., Perretti, M., \& Oliani, S. M. (2006). Spatial and temporal profiles for anti-inflammatory gene expression in leukocytes during a resolving model of peritonitis. $J$ Immunol, 176(7), 4410-4418. doi:10.4049/jimmunol.176.7.4410

Dufton, N., Hannon, R., Brancaleone, V., Dalli, J., Patel, H. B., Gray, M., . . . Flower, R. J. (2010). Antiinflammatory role of the murine formyl-peptide receptor 2: ligand-specific effects on leukocyte responses and experimental inflammation. J Immunol, 184(5), 2611-2619. doi:10.4049/jimmunol.0903526

Dvorak, A. M., Nabel, G., Pyne, K., Cantor, H., Dvorak, H. F., \& Galli, S. J. (1982). Ultrastructural identification of the mouse basophil. Blood, 59(6), 1279-1285.

Eke Gungor, H., Tahan, F., Gokahmetoglu, S., \& Saraymen, B. (2014). Decreased levels of lipoxin A4 and annexin A1 in wheezy infants. Int Arch Allergy Immunol, 163(3), 193-197. doi:10.1159/000358490

Frediani, J. K., Jones, D. P., Tukvadze, N., Uppal, K., Sanikidze, E., Kipiani, M., . . Ziegler, T. R. (2014). Plasma metabolomics in human pulmonary tuberculosis disease: a pilot study. PLOS ONE, 9(10), e108854. doi:10.1371/journal.pone.0108854

Fredman, G., Hellmann, J., Proto, J. D., Kuriakose, G., Colas, R. A., Dorweiler, B., . . Tabas, I. (2016). An imbalance between specialised pro-resolving lipid mediators and pro-inflammatory leukotrienes promotes instability of atherosclerotic plaques. Nat Commun, 7, 12859. doi:10.1038/ncomms12859

Fredman, G., Kamaly, N., Spolitu, S., Milton, J., Ghorpade, D., Chiasson, R., . . . Tabas, I. (2015). Targeted nanoparticles containing the proresolving peptide Ac2-26 protect against advanced atherosclerosis in hypercholesterolemic mice. Sci Transl Med, 7(275), 275ra220. doi:10.1126/scitranslmed.aaa1065

Fu, Y., Yip, A., Seah, P. G., Blasco, F., Shi, P. Y., \& Herve, M. (2014). Modulation of inflammation and pathology during dengue virus infection by p38 MAPK inhibitor SB203580. Antiviral Res, 110, 151157. doi:10.1016/j.antiviral.2014.08.004

Galvao, I., Vago, J. P., Barroso, L. C., Tavares, L. P., Queiroz-Junior, C. M., Costa, V. V., . . Teixeira, M. M. (2017). Annexin A1 promotes timely resolution of inflammation in murine gout. Eur J Immunol, 47(3), 585-596. doi:10.1002/eji.201646551

Gimenes, A. D., Andrade, T. R., Mello, C. B., Ramos, L., Gil, C. D., \& Oliani, S. M. (2015). Beneficial effect of annexin $A 1$ in a model of experimental allergic conjunctivitis. Exp Eye Res, 134, 24-32. doi:10.1016/j.exer.2015.03.013

Gobbetti, T., Coldewey, S. M., Chen, J., McArthur, S., le Faouder, P., Cenac, N., . . Perretti, M. (2014). Nonredundant protective properties of FPR2/ALX in polymicrobial murine sepsis. Proc Natl Acad Sci U S A, 111(52), 18685-18690. doi:10.1073/pnas.1410938111

Goncalves Pereira, M. H., Figueiredo, M. M., Queiroz, C. P., Magalhaes, T. V. B., Mafra, A., Diniz, L. M. O., ... da Costa Santiago, H. (2020). T cells producing multiple combinations of IFNgamma, TNF and IL10 are associated with mild forms of dengue infection. Immunology. doi:10.1111/imm.13185 
Hannon, R., Croxtall, J. D., Getting, S. J., Roviezzo, F., Yona, S., Paul-Clark, M. J., . . Flower, R. J. (2003). Aberrant inflammation and resistance to glucocorticoids in annexin 1-/- mouse. FASEB J, 17(2), 253-255. doi:10.1096/fj.02-0239fje

Hue, K. D., Tuan, T. V., Thi, H. T., Bich, C. T., Anh, H. H., Wills, B. A., \& Simmons, C. P. (2011). Validation of an internally controlled one-step real-time multiplex RT-PCR assay for the detection and quantitation of dengue virus RNA in plasma. J Virol Methods, 177(2), 168-173. doi:10.1016/j.jviromet.2011.08.002

JW, C. (1966). Maturation of rat mast cells. An electron microscope study. The Journal of cell biology, 31(3). doi:10.1083/jcb.31.3.563

Kusters, D. H., Chatrou, M. L., Willems, B. A., De Saint-Hubert, M., Bauwens, M., van der Vorst, E., . . . Reutelingsperger, C. P. (2015). Pharmacological Treatment with Annexin A1 Reduces Atherosclerotic Plaque Burden in LDLR-/- Mice on Western Type Diet. PLOS ONE, 10(6), e0130484. doi:10.1371/journal.pone.0130484

Lam, J. H., Chua, Y. L., Lee, P. X., Martinez Gomez, J. M., Ooi, E. E., \& Alonso, S. (2017). Dengue vaccineinduced CD8+ T cell immunity confers protection in the context of enhancing, interfering maternal antibodies. JCl Insight, 2(24). doi:10.1172/jci.insight.94500

Leoni, G., Neumann, P. A., Kamaly, N., Quiros, M., Nishio, H., Jones, H. R., . . Nusrat, A. (2015). Annexin A1-containing extracellular vesicles and polymeric nanoparticles promote epithelial wound repair. J Clin Invest, 125(3), 1215-1227. doi:10.1172/JCI76693

Locatelli, I., Sutti, S., Jindal, A., Vacchiano, M., Bozzola, C., Reutelingsperger, C., . . Perretti, M. (2014). Endogenous annexin $A 1$ is a novel protective determinant in nonalcoholic steatohepatitis in mice. Hepatology, 60(2), 531-544. doi:10.1002/hep.27141

Machado, M. G., Tavares, L. P., Souza, G. V. S., Queiroz-Junior, C. M., Ascencao, F. R., Lopes, M. E., . . Sousa, L. P. (2020). The Annexin A1/FPR2 pathway controls the inflammatory response and bacterial dissemination in experimental pneumococcal pneumonia. FASEB J, 34(2), 2749-2764. doi:10.1096/fj.201902172R

Marques, R. E., Guabiraba, R., Del Sarto, J. L., Rocha, R. F., Queiroz, A. L., Cisalpino, D., . . Teixeira, M. M. (2015). Dengue virus requires the CC-chemokine receptor CCR5 for replication and infection development. Immunology, 145(4), 583-596. doi:10.1111/imm.12476

Melo, R. C. N., Spencer, L. A., Perez, S. A., Neves, J. S., Bafford, S. P., Morgan, E. S., . . Weller, P. F. (2009). Vesicle-mediated secretion of human eosinophil granule-derived major basic protein. Lab Invest, 89(7), 769-781. doi:labinvest200940 [pii]

10.1038/labinvest.2009.40

Modhiran, N., Watterson, D., Muller, D. A., Panetta, A. K., Sester, D. P., Liu, L., . . Young, P. R. (2015). Dengue virus NS1 protein activates cells via Toll-like receptor 4 and disrupts endothelial cell monolayer integrity. Sci Trans/ Med, 7(304), 304ra142. doi:10.1126/scitransImed.aaa3863

Molas, R. B., Ribeiro, M. R., Ramalho Dos Santos, M. J. C., Borbely, A. U., Oliani, D. V., Oliani, A. H., ... Oliani, S. M. (2020). The involvement of annexin A1 in human placental response to maternal Zika virus infection. Antiviral Res, 179, 104809. doi:10.1016/j.antiviral.2020.104809

Morita, M., Kuba, K., Ichikawa, A., Nakayama, M., Katahira, J., Iwamoto, R., . . I Imai, Y. (2013). The lipid mediator protectin D1 inhibits influenza virus replication and improves severe influenza. Cell, 153(1), 112-125. doi:10.1016/j.cell.2013.02.027

Morrison, J., Rathore, A. P. S., Mantri, C. K., Aman, S. A. B., Nishida, A., \& St John, A. L. (2017). Transcriptional Profiling Confirms the Therapeutic Effects of Mast Cell Stabilization in a Dengue Disease Model. J Virol, 91(18). doi:10.1128/JVI.00617-17 
Murri, M., Insenser, M., Bernal-Lopez, M. R., Perez-Martinez, P., Escobar-Morreale, H. F., \& Tinahones, F. J. (2013). Proteomic analysis of visceral adipose tissue in pre-obese patients with type 2 diabetes. Mol Cell Endocrinol, 376(1-2), 99-106. doi:10.1016/j.mce.2013.06.010

Oliveira, L. G., Souza-Testasicca, M. C., Vago, J. P., Figueiredo, A. B., Canavaci, A. M., Perucci, L. O., . . Fernandes, A. P. (2017). Annexin A1 Is Involved in the Resolution of Inflammatory Responses during Leishmania braziliensis Infection. J Immunol, 198(8), 3227-3236. doi:10.4049/jimmunol.1602028

Organisation, W. H. (2009). Dengue guidelines for diagnosis, treatment, prevention and control : new edition. : World Health Organization.

Parisi, J. D. S., Correa, M. P., \& Gil, C. D. (2019). Lack of Endogenous Annexin A1 Increases Mast Cell Activation and Exacerbates Experimental Atopic Dermatitis. Cells, 8(1). doi:10.3390/cells8010051

Perretti, M., Ahluwalia, A., Harris, J. G., Goulding, N. J., \& Flower, R. J. (1993). Lipocortin-1 fragments inhibit neutrophil accumulation and neutrophil-dependent edema in the mouse. A qualitative comparison with an anti-CD11b monoclonal antibody. J Immunol, 151(8), 4306-4314.

Radinger, M., Jensen, B. M., Swindle, E., \& Gilfillan, A. M. (2015). Assay of mast cell mediators. Methods Mol Biol, 1220, 307-323. doi:10.1007/978-1-4939-1568-2_19

Ramon, S., Baker, S. F., Sahler, J. M., Kim, N., Feldsott, E. A., Serhan, C. N., . . Phipps, R. P. (2014). The specialised proresolving mediator 17-HDHA enhances the antibody-mediated immune response against influenza virus: a new class of adjuvant? J Immunol, 193(12), 6031-6040. doi:10.4049/jimmunol.1302795

Rathore, A. P., Mantri, C. K., Aman, S. A., Syenina, A., Ooi, J., Jagaraj, C. J., . . St John, A. L. (2019). Dengue virus-elicited tryptase induces endothelial permeability and shock. J Clin Invest, 129(10), 41804193. doi:10.1172/JCl128426

Rathore, A. P. S., Senanayake, M., Athapathu, A. S., Gunasena, S., Karunaratna, I., Leong, W. Y., ... St John, A. L. (2020). Serum chymase levels correlate with severe dengue warning signs and clinical fluid accumulation in hospitalised pediatric patients. Sci Rep, 10(1), 11856. doi:10.1038/s41598-02068844-z

Saria, A., \& Lundberg, J. M. (1983). Evans blue fluorescence: quantitative and morphological evaluation of vascular permeability in animal tissues. Journal of Neuroscience Methods, 8(1), 41-49. doi:10.1016/0165-0270(83)90050-x

Schett, G., \& Neurath, M. F. (2018). Resolution of chronic inflammatory disease: universal and tissuespecific concepts. Nat Commun, 9(1), 3261. doi:10.1038/s41467-018-05800-6

Schloer, S., Hubel, N., Masemann, D., Pajonczyk, D., Brunotte, L., Ehrhardt, C., . . Rescher, U. (2019). The annexin A1/FPR2 signaling axis expands alveolar macrophages, limits viral replication, and attenuates pathogenesis in the murine influenza $A$ virus infection model. FASEB J, fj201901265R. doi:10.1096/fj.201901265R

Sena, A., Grishina, I., Thai, A., Goulart, L., Macal, M., Fenton, A., . . Sankaran-Walters, S. (2013). Dysregulation of anti-inflammatory annexin A1 expression in progressive Crohns Disease. PLoS $O N E, 8(10)$, e76969. doi:10.1371/journal.pone.0076969

Sheikh, M. H., \& Solito, E. (2018). Annexin A1: Uncovering the Many Talents of an Old Protein. Int J Mol Sci, 19(4). doi:10.3390/ijms19041045

Shepard, D. S., Undurraga, E. A., Halasa, Y. A., \& Stanaway, J. D. (2016). The global economic burden of dengue: a systematic analysis. The Lancet Infectious Diseases, 16(8), 935-941. doi:10.1016/s14733099(16)00146-8

Shirey, K. A., Lai, W., Pletneva, L. M., Karp, C. L., Divanovic, S., Blanco, J. C., \& Vogel, S. N. (2014). Role of the lipoxygenase pathway in RSV-induced alternatively activated macrophages leading to resolution of lung pathology. Mucosal Immunol, 7(3), 549-557. doi:10.1038/mi.2013.71 
Shresta, S., Kyle, J. L., Snider, H. M., Basavapatna, M., Beatty, P. R., \& Harris, E. (2004). Interferondependent immunity is essential for resistance to primary dengue virus infection in mice, whereas T- and B-cell-dependent immunity are less critical. J Virol, 78(6), 2701-2710. doi:10.1128/jvi.78.6.2701-2710.2004

Sinniah, A., Yazid, S., Bena, S., Oliani, S. M., Perretti, M., \& Flower, R. J. (2019). Endogenous Annexin-A1 Negatively Regulates Mast Cell-Mediated Allergic Reactions. Front Pharmacol, 10, 1313. doi:10.3389/fphar.2019.01313

Sinniah, A., Yazid, S., Perretti, M., Solito, E., \& Flower, R. J. (2016). The role of the Annexin-A1/FPR2 system in the regulation of mast cell degranulation provoked by compound $48 / 80$ and in the inhibitory action of nedocromil. Int Immunopharmacol, 32, 87-95. doi:10.1016/j.intimp.2016.01.003

Souza, D. G., Fagundes, C. T., Sousa, L. P., Amaral, F. A., Souza, R. S., Souza, A. L., . . Teixeira, M. M. (2009). Essential role of platelet-activating factor receptor in the pathogenesis of Dengue virus infection. Proc Natl Acad Sci U S A, 106(33), 14138-14143. doi:10.1073/pnas.0906467106

St John, A. L., Abraham, S. N., \& Gubler, D. J. (2013). Barriers to preclinical investigations of anti-dengue immunity and dengue pathogenesis. Nat Rev Microbiol, 11(6), 420-426. doi:10.1038/nrmicro3030

St John, A. L., Rathore, A. P., Raghavan, B., Ng, M. L., \& Abraham, S. N. (2013). Contributions of mast cells and vasoactive products, leukotrienes and chymase, to dengue virus-induced vascular leakage. Elife, 2, e00481. doi:10.7554/eLife.00481

St John, A. L., Rathore, A. P., Yap, H., Ng, M. L., Metcalfe, D. D., Vasudevan, S. G., \& Abraham, S. N. (2011). Immune surveillance by mast cells during dengue infection promotes natural killer (NK) and NKTcell recruitment and viral clearance. Proc Natl Acad Sci U S A, 108(22), 9190-9195. doi:10.1073/pnas.1105079108

Stanaway, J. D., Shepard, D. S., Undurraga, E. A., Halasa, Y. A., Coffeng, L. E., Brady, O. J., . . Murray, C. J. L. (2016). The global burden of dengue: an analysis from the Global Burden of Disease Study 2013. The Lancet Infectious Diseases, 16(6), 712-723. doi:10.1016/s1473-3099(16)00026-8

Sugimoto, M. A., Vago, J. P., Perretti, M., \& Teixeira, M. M. (2019). Mediators of the Resolution of the Inflammatory Response. Trends Immunol, 40(3), 212-227. doi:10.1016/j.it.2019.01.007

Sugimoto, M. A., Vago, J. P., Teixeira, M. M., \& Sousa, L. P. (2016). Annexin A1 and the Resolution of Inflammation: Modulation of Neutrophil Recruitment, Apoptosis, and Clearance. J Immunol Res, 2016, 8239258. doi:10.1155/2016/8239258

Syenina, A., Jagaraj, C. J., Aman, S. A., Sridharan, A., \& St John, A. L. (2015). Dengue vascular leakage is augmented by mast cell degranulation mediated by immunoglobulin Fcgamma receptors. Elife, 4. doi:10.7554/eLife.05291

Tabas, I., \& Glass, C. K. (2013). Anti-inflammatory therapy in chronic disease: challenges and opportunities. Science, 339(6116), 166-172. doi:10.1126/science.1230720

Tavares, L. P., Garcia, C. C., Vago, J. P., Queiroz-Junior, C. M., Galvao, I., David, B. A., . . Sousa, L. P. (2016). Inhibition of Phosphodiesterase-4 during Pneumococcal Pneumonia Reduces Inflammation and Lung Injury in Mice. Am J Respir Cell Mol Biol, 55(1), 24-34. doi:10.1165/rcmb.2015-00830C

The Lancet Infectious, D. (2018). The dengue vaccine dilemma. The Lancet Infectious Diseases, 18(2), 123. doi:10.1016/s1473-3099(18)30023-9

Thul, S., Labat, C., Temmar, M., Benetos, A., \& Back, M. (2017). Low salivary resolvin D1 to leukotriene B4 ratio predicts carotid intima media thickness: A novel biomarker of non-resolving vascular inflammation. Eur J Prev Cardiol, 24(9), 903-906. doi:10.1177/2047487317694464

Tissera, H., Rathore, A. P. S., Leong, W. Y., Pike, B. L., Warkentien, T. E., Farouk, F. S., . . St John, A. L. (2017). Chymase Level Is a Predictive Biomarker of Dengue Hemorrhagic Fever in Pediatric and Adult Patients. J Infect Dis, 216(9), 1112-1121. doi:10.1093/infdis/jix447 
Tzelepis, F., Verway, M., Daoud, J., Gillard, J., Hassani-Ardakani, K., Dunn, J., . . . Divangahi, M. (2015). Annexin1 regulates DC efferocytosis and cross-presentation during Mycobacterium tuberculosis infection. J Clin Invest, 125(2), 752-768. doi:10.1172/JCI77014

Vago, J. P., Nogueira, C. R., Tavares, L. P., Soriani, F. M., Lopes, F., Russo, R. C., . . Sousa, L. P. (2012). Annexin A1 modulates natural and glucocorticoid-induced resolution of inflammation by enhancing neutrophil apoptosis. J Leukoc Biol, 92(2), 249-258. doi:10.1189/jlb.0112008

Vanessa, K. H., Julia, M. G., Wenwei, L., Michelle, A. L., Zarina, Z. R., Lina, L. H., \& Sylvie, A. (2015). Absence of Annexin A1 impairs host adaptive immunity against Mycobacterium tuberculosis in vivo. Immunobiology, 220(5), 614-623. doi:10.1016/j.imbio.2014.12.001

Vong, L., Ferraz, J. G., Dufton, N., Panaccione, R., Beck, P. L., Sherman, P. M., . . Wallace, J. L. (2012). Upregulation of Annexin-A1 and lipoxin $A(4)$ in individuals with ulcerative colitis may promote mucosal homeostasis. PLOS ONE, 7(6), e39244. doi:10.1371/journal.pone.0039244

WHO. (2009). Dengue: Guidelines for Diagnosis, Treatment, Prevention and Control: New Edition. (9789241547871). Geneva Retrieved from http://www.ncbi.nlm.nih.gov/pubmed/23762963.

Yazid, S., Sinniah, A., Solito, E., Calder, V., \& Flower, R. J. (2013). Anti-allergic cromones inhibit histamine and eicosanoid release from activated human and murine mast cells by releasing Annexin A1. PLoS ONE, 8(3), e58963. doi:10.1371/journal.pone.0058963 


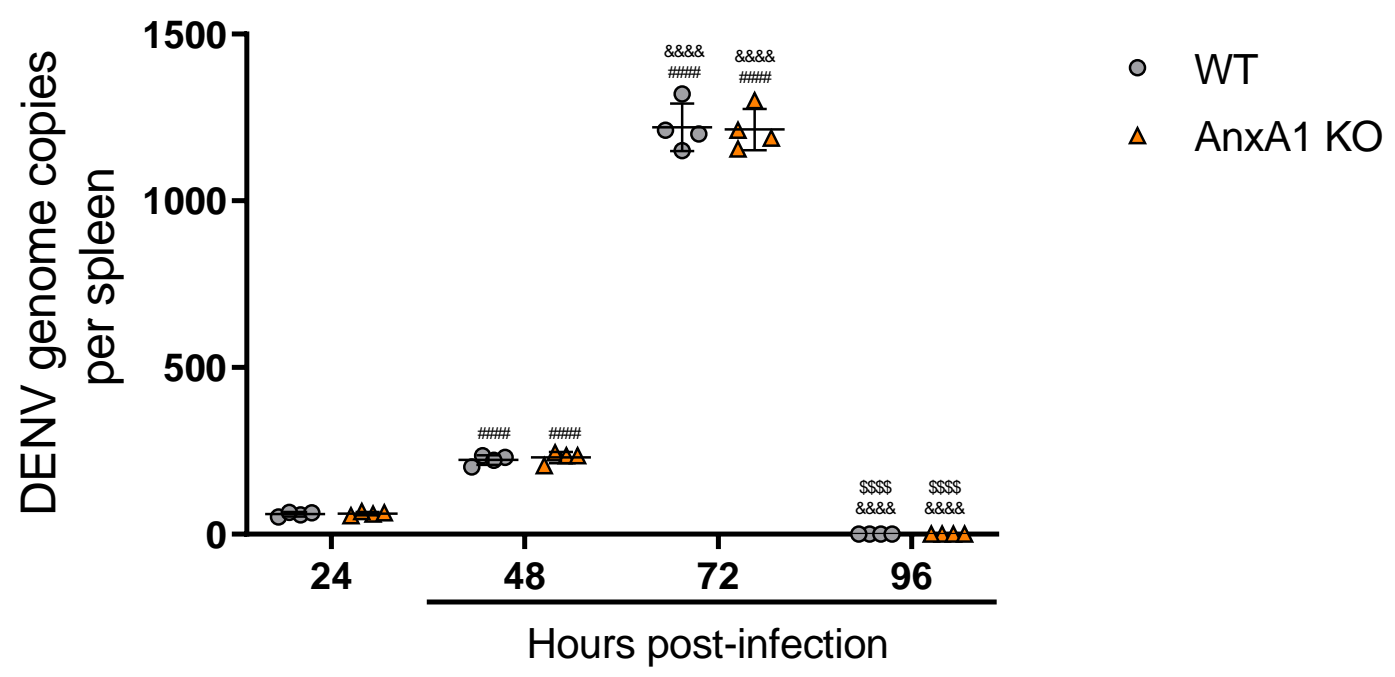

856 Figure 2-figure supplement 1. DENV virus replication is not altered by the absence of Annexin A1.

857 5-week-old C57BL/6 WT mice $(\mathrm{n}=4)$ were inoculated with $1 \times 10^{6} \mathrm{PFU}$ of DENV-2 by the intravenous (i.v.)

858 route. Mice were culled in the indicated time points after infection, and the spleen was harvested virus RNA

859 quantification. After cDNA conversion, real-time reverse-transcription PCR (RT-PCR) was performed to

860 quantitate DENV genome copies in the spleen, which was normalised to spleen mass. Results are expressed

861 as mean (horizontal bars) \pm SD. Differences over time were compared by two-way ANOVA followed by

862 Turkey’s multiple comparison test: \#\#\#\#p<0.0001 versus $24 \mathrm{~h}$-infected group; \&\&\&\& $<<0.0001$ versus $48 \mathrm{~h}-$

863 infected group; ${ }^{\$ \$ \$}<<0.0001$ versus $72 \mathrm{~h}$-infected group. There was no statistical difference between the

864 genotypes, as evaluated by two-way ANOVA followed by Sidak's multiple comparison test. 


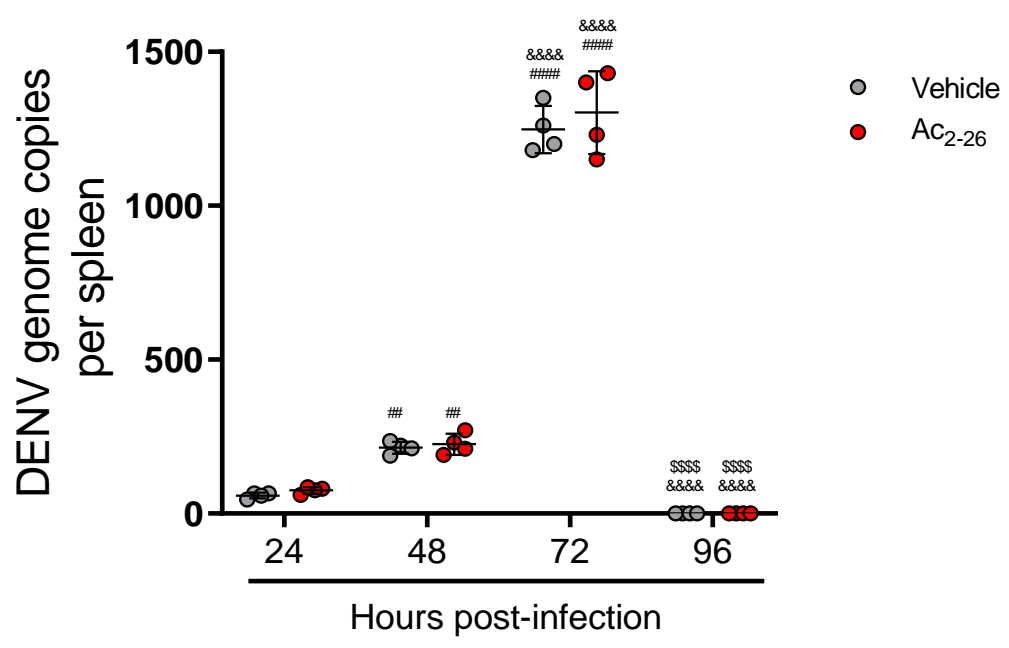

Figure 3-figure supplement 1. DENV virus replication is not altered by treatment with AnxA1

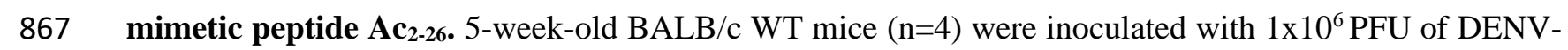

8682 by the intravenous (i.v.) route. Mice were treated or not with $150 \mu \mathrm{g}$ of $\mathrm{Ac}_{2-26}$ at the time of infection and

869 daily thereafter by the intraperitoneal (i.p.) route. Mice were culled in the indicated time points after

870 infection, and the spleen was harvested virus RNA quantification. After cDNA conversion, RT-PCR was

871 performed to quantitate DENV genome copies in the spleen, which was normalised to spleen mass. All

872 results are expressed as mean values (horizontal bars). Results are expressed as mean (horizontal bars).

873 Differences over time were compared by two-way ANOVA followed by Turkey's multiple comparison

874 test: ${ }^{\#} \mathrm{p}<0.01$ and ${ }^{\# \# \#} \mathrm{p}<0.0001$ versus $24 \mathrm{~h}$-infected group; \&\&\&\& $\mathrm{p}<0.0001$ versus $48 \mathrm{~h}-\mathrm{infected}$ group;

$875 \$ \$ \$ p<0.0001$ versus $72 \mathrm{~h}$-infected group. There was no statistical difference between the treated and

876 untreated groups, as evaluated by two-way ANOVA followed by Sidak's multiple comparison test. 


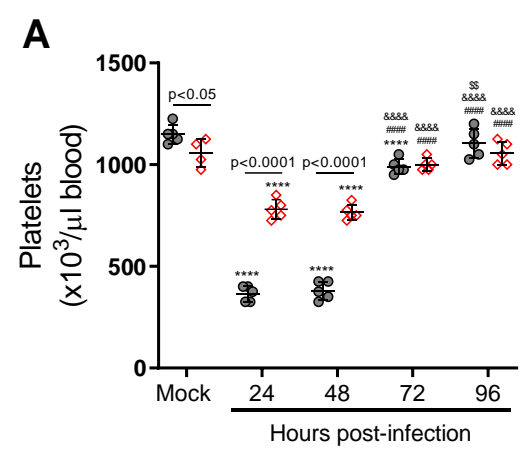

B

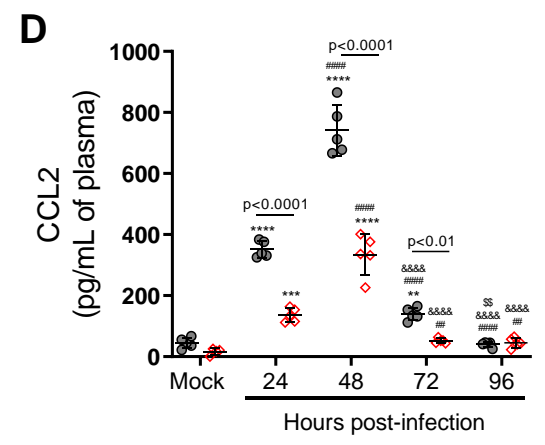

C

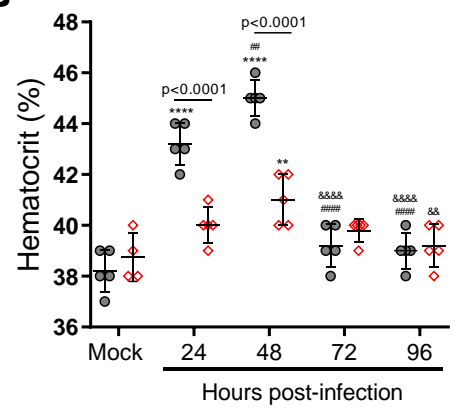

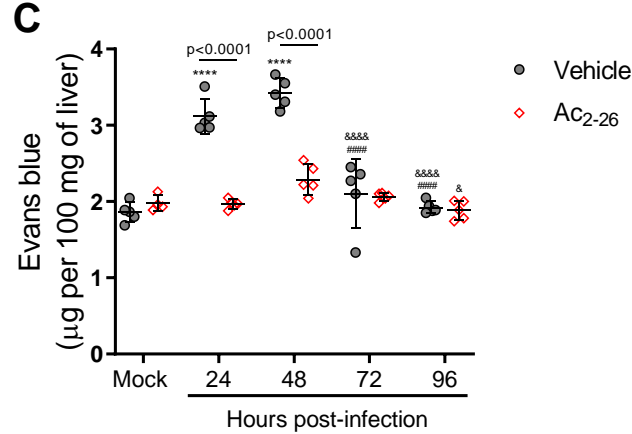

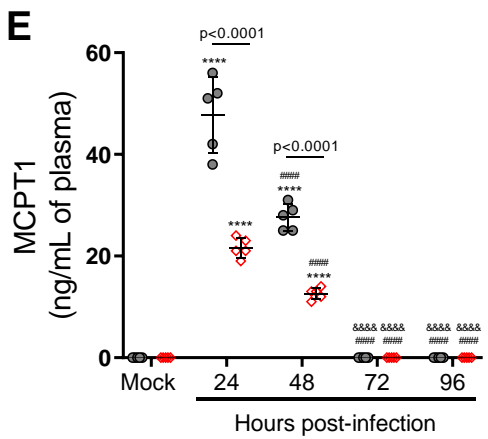

877

878

879

880

881

882

883

884

885

886

887

888

889

890

891

Figure 3-figure supplement 2. Ac2-26 peptide improve DENV-induced manifestations in AnxA1 KO

mice. 5-week-old AnxA1 KO mice (BALB/c background) were mock-infected or inoculated with 1x10 PFU of DENV-2 by the intravenous route $(n=5)$. Mice were treated with PBS (grey circle) or $150 \mu$ g of $\mathrm{Ac}_{2-26}$ (red open diamond) at the time of infection and daily after that by the intraperitoneal route. Mice were culled in the indicated time points after infection, and blood and tissue were collected for the following analysis: (A) platelet counts, shown as the number of platelets $\times 10^{3} / \mu \mathrm{L}$ of blood; (B) haematocrit levels, shown as \% volume occupied by red blood cells; (C) vascular leakage assay with Evans's blue dye, expressed as the amount of Evans Blue per 100mg of the liver. Concentrations of (D) MCPT1 and (E) CCL2 in plasma, quantified by ELISA and expressed as quantity per ml of plasma. All results are expressed as median (horizontal bars). All results are expressed as mean (horizontal bars). Differences over time were compared by two-way ANOVA followed by Turkey's multiple comparison test: ${ }^{\mathrm{p}} \mathrm{p}<0.05, * * \mathrm{p}<0.01$, $* * * \mathrm{p}<0.001$ and $* * * * \mathrm{p}<0.0001$ versus mock-infected group; ${ }^{*} \mathrm{p}<0.05,{ }^{\#} \mathrm{p}<0.01,{ }^{\# \#} \mathrm{p}<0.001$ and $\# \# \#$ p $<0.0001$ versus $24 \mathrm{~h}-$ infected group; ${ }^{\&} \mathrm{p}<0.05,{ }^{\& \&} \mathrm{p}<0.01$, ${ }^{\& \& \&} \mathrm{p}<0.001$ and ${ }^{\& \& \& \&} \mathrm{p}<0.0001$ versus $48 \mathrm{~h}-$ infected group; ${ }^{\$} \mathrm{p}<0.05,{ }^{\$} \mathrm{p}<0.01,{ }^{\$ \$} \mathrm{p}<0.001$ and ${ }^{\$ \$ \$} \mathrm{p}<0.0001$ versus $72 \mathrm{~h}$-infected group; or as indicated 
bioRxiv preprint doi: https://doi.org/10.1101/2021.11.02.466887; this version posted November 3, 2021. The copyright holder for this preprint

(which was not certified by peer review) is the author/funder, who has granted bioRxiv a license to display the preprint in perpetuity. It is made available under aCC-BY 4.0 International license.

892 in the graphs. Differences between vehicle- and AnxA1 peptide-treated animals were compared by two-

893 way ANOVA followed by Sidak's multiple comparison test, as indicated in the graphs. 


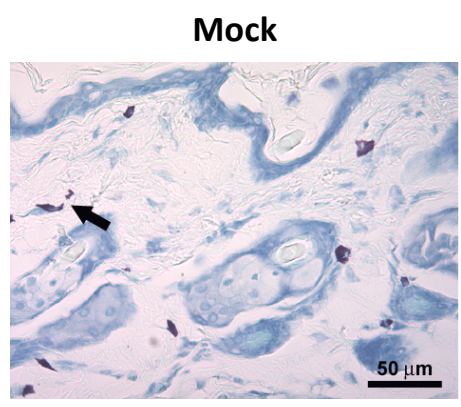

DENV-2

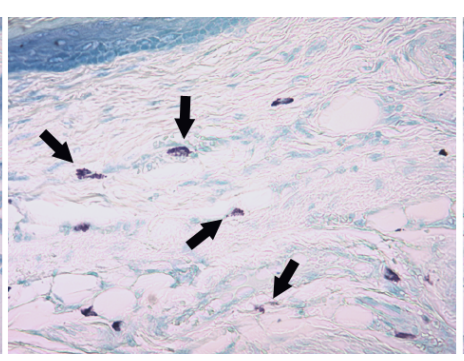

DENV-2 + Ac 2-26 i.pl.

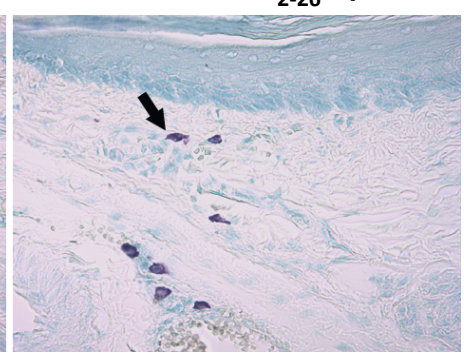

DENV-2 + $\mathrm{Ac}_{2-26}$ i.p.

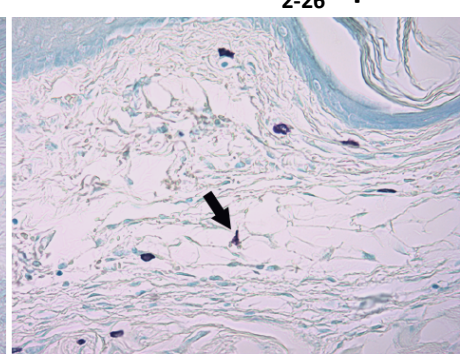

Figure 6-figure supplement 1. Effect of $\mathrm{Ac}_{2-26}$ treatment in mast cell degranulation induced by DENV-

2. Representative images of footpad sections of $\mathrm{Balb} / \mathrm{c}$ mice pretreated with $\mathrm{Ac}_{2-26}$ via footpad (i.pl.) or intraperitoneal (i.p) injections and infected with DENV-2 via footpad injections. Three hours post-infection, mice were euthanised and had their hind paws removed for the histological analysis of MC degranulation. Arrows indicate degranulated cells, visualised by toluidine blue staining.

Table 1: Demographics and laboratory characteristics of the study population from the control group, nonsevere dengue (non-SD, outpatients), and severe dengue (SD, inpatients) groups during seasonal transmission 2013 to 2016.

\begin{tabular}{|l|c|c|c|}
\hline $\begin{array}{c}\text { Characteristics and diagnosis of } \\
\text { the study population }\end{array}$ & Control (n=41) & Non-SD (n=31) & SD (n=29) \\
\hline Age $^{\text {a }}$ & $30(19-58) * *$ & $31(17-65) *$ & $42(19-76)$ \\
\hline Gender (F) & $71 \%(29 / 41)$ & $55 \%(17 / 31)$ & $52 \%(15 / 29)$ \\
\hline RT-PCR (n) & $0 \%(0 / 41)$ & $74 \%(23 / 31)$ & $38 \%(11 / 29)$ \\
\hline ELISA IgM (n) & $0 \%(0 / 41)$ & $61 \%(19 / 31)$ & $100 \%(29 / 29)$ \\
\hline $\begin{array}{l}\text { Blood collection 1-5 days after } \\
\text { symptom onset }\end{array}$ & - & $58 \%(18 / 31)$ & $45 \%(13 / 29)$ \\
\hline $\begin{array}{l}\text { Blood collection 6-12 days after } \\
\text { symptom onset }\end{array}$ & - & $42 \%(13 / 31)$ & $55 \%(16 / 29)$ \\
\hline
\end{tabular}

a Geometric Mean (min-max).

904 Age: Kruskal-Wallis Test $\mathrm{P}<0.003$

905 Gender: Fisher Test $\mathrm{P}>0.1$

906

Blood collection: Fisher Test $\mathrm{P}>0.4$ 
907 Supplementary Table 1: oligo primers and probes used in clinical samples.

908

\begin{tabular}{cl}
\hline Serotype & \multicolumn{1}{c}{ Sequence of Primers and Probes (5'-3') } \\
\hline DENV1-F & ATCCATGCCCAYCACCAAT \\
DENV1-R & TGTGGGTTTTGTCCTCCATC \\
DENV1-Probes & FAM-TCAGTGTGGAATAGGGTTTGGATAGAGGAA-TAMRA \\
\hline DENV2-F & TCCATACACGCCAAACATGAA \\
DENV2-R & GGGATTTCCTCCCATGATTCC \\
DENV2- Probes & FAM-AGGGTGTGGATTCGAGAAAACCCATGG-TAMRA \\
\hline DENV3-F & TTTCTGCTCCCACCACTTTC \\
DENV3-R & CCATCCYGCTCCTTGAGA \\
DENV3- Probes & TET-AAGAAAGTTGGTAGTTCCCTGCAGACCCCA-TAMRA \\
\hline DENV4-F & GYGTGGTGAAGCCYCTRGAT \\
DENV4-R & AGTGARCGGCCATCCTTCAT \\
DENV4- Probes & TET-ACTTCCCTCCTCTTYTTGAACGACATGGGA-TAMRA \\
\hline
\end{tabular}

